\title{
Ligand-Dependent Recruitment of the ErbB4 Signaling Complex into Neuronal Lipid Rafts
}

\author{
Li Ma, ${ }^{1,2 *}$ Yang Z. Huang, ${ }^{1 *}$ Graham M. Pitcher, ${ }^{3}$ Juli G. Valtschanoff, ${ }^{4}$ Ying H. Ma, ${ }^{1}$ Lin Y. Feng, ${ }^{2}$ Bai Lu, ${ }^{5}$ Wen C. Xiong, ${ }^{6}$ \\ Michael W. Salter, ${ }^{3}$ Richard J. Weinberg, ${ }^{4}$ and Lin Mei ${ }^{1}$ \\ ${ }^{1}$ Departments of Neurobiology, Pathology, and Physical Medicine and Rehabilitation, University of Alabama at Birmingham, Civitan International Research \\ Center, Birmingham, Alabama 35294, ${ }^{2}$ Institute of Neuroscience, Shanghai Institutes for Biological Sciences, Chinese Academy of Sciences, Shanghai \\ 200031, China, ${ }^{3}$ Programmes in Brain and Behaviour and Cell Biology, Hospital for Sick Children, and Department of Physiology, University of Toronto, \\ Toronto, Ontario M5G 1X8, Canada, ${ }^{4}$ Department of Cell and Developmental Biology and Neuroscience Center, University of North Carolina, Chapel Hill, \\ North Carolina 27599, ${ }^{5}$ Unit on Synapse Development and Plasticity, National Institute of Child Health and Human Development, National Institutes of \\ Health, Bethesda, Maryland 20892, and 'Department of Pathology, University of Alabama at Birmingham, Birmingham, Alabama 35294
}

Neuregulin (NRG) regulates synapse formation and synaptic plasticity, but little is known about the regulation of NRG signaling at synapses. Here we show that the NRG receptor ErbB4 was localized in anatomically defined postsynaptic densities in the brain. In cultured cortical neurons, ErbB4 was recruited to the neuronal lipid raft fraction after stimulation by NRG. Along with ErbB4, adaptor proteins Grb2 and Shc were translocated to lipid rafts by NRG stimulation. In transfected human embryonic kidney 293 cells, the partitioning of ErbB4 into a detergent-insoluble fraction that includes lipid rafts was increased by PSD-95 (postsynaptic density-95), through interaction of the ErbB4 C terminus with the PDZ [PSD-95/Discs large/zona occludens-1] domains of PSD-95. Disruption of lipid rafts inhibited NRG-induced activation of Erk and prevented NRG-induced blockade of induction of long-term potentiation at hippocampal CA1 synapses. Thus, our results indicate that NRG stimulation causes translocation of ErbB4 into lipid rafts and that lipid rafts are necessary for signaling by ErbB4.

Key words: lipid rafts; ErbB4; NRG; PSD-95; postsynaptic density; long-term potentiation; synaptic plasticity

\section{Introduction}

Neuregulins (NRGs), a family of structurally related polypeptides, activate the ErbB family of receptor tyrosine kinases, including ErbB2, ErbB3, and ErbB4. The role of NRG signaling in neural development has been studied extensively (Fischbach and Rosen, 1997; Buonanno and Fischbach, 2001; Lemke, 2001), although the embryonic lethality associated with mutation of NRG1, ErbB2, or ErbB4 (Gassmann et al., 1995; Lee et al., 1995; Meyer and Birchmeier, 1995; Kramer et al., 1996; Wolpowitz et al., 2000) has limited the scope of these studies. Deletion of NRG, NRG-Ig, or ErbB2 impairs development of cranial sensory ganglia (Meyer and Birchmeier, 1995; Kramer et al., 1996), and axons from cranial ganglia are mistargeted in ErbB4-/- mice (Gassmann et al., 1995). NRG1 and ErbB2 appear to be essential for the development of the peripheral nervous system. Deletion of the NRG-cysteine-rich domain or ErbB2 also causes abnormal development of motoneuron axons (Morris et al., 1999; Woldeyesus et

\footnotetext{
Received July 17, 2002; revised Jan. 21, 2003; accepted Jan. 31, 2003

This work was supported in part by a faculty development award from the Howard Hughes Medical Institute at the University of Alabama at Birmingham and National Institutes of Health/National Institute of Neurological Disorders and Stroke Grants NS40480 (L.M.) and NS39444 (R.J.W.), by a start-up grant from the University of Alabama at Birmingham (W.C.X.), by Major State Basic Research Program Grant G200077800 (L.Y.F.), and by a grant from the Canadian Institutes of Health Research (CIHR) (M.W.S). M.W.S. is a CIHR Investigator, and G.M.P. is a CIHR Postdoctoral Fellow. We are grateful to Dr. M. Sliwkowski for valuable reagents.

* L. M. and Y. Z. H. contributed equally to this work.

Correspondence should be addressed to Dr. Lin Mei, Department of Neurobiology, University of Alabama at Birmingham, School of Medicine, 516 Civitan International Research Center, 1719 Sixth Avenue, South, Birmingham, AL 35294-0021. E-mail: Imei@nrc.uab.edu.

Copyright $\odot 2003$ Society for Neuroscience $\quad 0270-6474 / 03 / 233164-12 \$ 15.00 / 0$
}

al., 1999; Wolpowitz et al., 2000). In addition, NRG signaling appears to be required for survival, proliferation, and differentiation of multiple types of glia (Meyer and Birchmeier, 1995; Adlkofer and Lai, 2000; Garratt et al., 2000).

Rather than being expressed evenly on the cell surface, ErbB proteins are concentrated in postsynaptic membranes at the neuromuscular junction (Altiok et al., 1995; Moscoso et al., 1995; Zhu et al., 1995; Trinidad et al., 2000; Huang et al., 2002), and perhaps also at the postsynaptic density (PSD) in the brain (Garcia et al., 2000; Huang et al., 2000). The PSD is an electron-dense structure located beneath the postsynaptic membrane in register with the active zone of the presynaptic terminal in the CNS. This submembrane specialization contains receptors for excitatory amino acids and ion channels necessary for neurotransmission, as well as essential enzymes for signaling at the synapse (Kennedy, 1997; Ziff, 1997). The PSD is believed to be important for adhesion, clustering of neurotransmitter receptors, and regulation of receptor function (Kennedy, 1997; Craven and Bredt, 1998; Garner et al., 2000; Sheng and Sala, 2001). Biochemical studies indicate that ErbB4 is enriched in the PSD (Huang et al., 2000), and light microscopic immunocytochemistry shows ErbB4 to colocalize with PSD markers (Garcia et al., 2000; Huang et al., 2000). The apparent localization of ErbB proteins at the PSD suggests that NRG signaling may be important in regulating synaptic function, and we have recently demonstrated that NRG blocks induction of long-term potentiation (LTP) at excitatory synapses in CA1 hippocampal neurons (Huang et al., 2000). Intriguingly, recent studies suggest that ErbB4 is a substrate of presenilindependent $\gamma$-secretase activity (Ni et al., 2001; Lee et al., 2002) 
and that NRG1 may be a candidate gene for schizophrenia (Stefansson et al., 2002).

An important unresolved issue is how NRG signaling occurs at excitatory synapses in the CNS. In the present study, we sought to address this question by investigating whether the NRG receptor ErbB4 concentrates in the anatomical PSD at the electron microscopic level, and in lipid rafts, less fluid microdomains within plasma membranes that are enriched in sphingolipids and cholesterol (Simons and Ikonen, 1997; Brown and London, 1998; Suzuki, 2002). We asked whether NRG causes recruitment of ErbB4 and associated signaling molecules to neuronal lipid rafts. Furthermore, we investigated the effects of disruption of lipid rafts on NRG signaling and function at CNS synapses. Our findings demonstrate a critical role for lipid rafts in NRG signaling and modulation of synaptic plasticity in the CNS.

\section{Materials and Methods}

\section{Materials}

Primary antibodies were from Upstate Biotechnology (Lake Placid, NY; PSD-95, 05-427), Santa Cruz Biotechnology [Santa Cruz, CA; ErbB4, sc-283; Shc, sc-967; Grb2, sc-255; transferrin receptor (TfR), sc-9099], BD Transduction Labs (caveolin, C13630; TrkB, 610101; PSD-95, P43520 and phosphotyrosine, E120H), Promega (Madison, WI; active Erk, V8031), and Sigma (St. Louis, MO; FLAG, F3165). For immunoblotting, the dilution of the antibodies was 1:1000 except for $\mathrm{E} 120 \mathrm{H}$ (1:2500) and V8031 (1:5000). For electron microscopy, the dilution of sc-283 was $1: 1000$ and of P43520 was $1: 100$. Methyl- $\beta$-cyclodextrin (MCD) (M1356) and filipin (F4767) were from Sigma. For NRG stimulation, we used a recombinant polypeptide containing the entire epidermal growth factor domain of the $\beta$-type NRG-1 $\left(\mathrm{rHRG}_{\beta 177-244}\right)$ (Holmes et al., 1992), which binds to ErbB3 and ErbB4 and thus induces tyrosine phosphorylation of ErbB2, ErbB3, and ErbB4 (Jones et al., 1998; Tanowitz et al., 1999; Huang et al., 2000). ErbB4 (aa 26-1308) was subcloned into BamHI-SalI sites of pFLAG-CMV downstream of an artificial signal peptide sequence and a FLAG epitope. ErbB4-influenza hemagglutinin (HA) and PSD-95 $\triangle \mathrm{PDZ}$ have been described previously (Huang et al., 2000, 2001).

\section{Electron microscopy}

Three male Sprague Dawley rats, 200-400 gm (Charles River, Raleigh, $\mathrm{NC})$, were deeply anesthetized ( $80 \mathrm{mg} / \mathrm{kg}$ pentobarbital, i.p.) and fixed with $4 \%$ paraformaldehyde and $2 \%$ glutaraldehyde; brains were processed for osmium-free embedment according to the methods of Phend et al. (1995). Briefly, sections on ice were treated for $45 \mathrm{~min}$ in $1 \%$ tannic acid in $0.1 \mathrm{M}$ maleate buffer (MB), $\mathrm{pH} 6.0$, rinsed in $\mathrm{MB}$, immersed for 40 min in $1 \%$ uranyl acetate, $0.5 \%$ iridium tetrabromide (Pfaltz and Bauer, Waterbury, CT) in $\mathrm{MB}, 50$ and $70 \%$ ethanol for $5 \mathrm{~min}, 1 \%$ p-phenylenediamine hydrochloride in 70\% ethanol for $15 \mathrm{~min}, 1 \%$ uranyl acetate in $70 \%$ ethanol for $40 \mathrm{~min}$, and then dehydrated in ethanol. For Epon embedment, sections were immersed in propylene oxide and infiltrated with Epon-Spurr (EMS, Fort Washington, PA) and then sandwiched between strips of plastic film and polymerized at $60^{\circ} \mathrm{C}$ for $24 \mathrm{hr}$. For Lowicryl embedment, sections were infiltrated with Lowicryl HM-20 (EMS), sandwiched in plastic, and polymerized at $-10^{\circ} \mathrm{C}$ for $48 \mathrm{hr}$ under ultraviolet illumination.

Thin sections were cut and collected on 300-mesh uncoated nickel grids and stained for ErbB4 using the immunogold approach described in Phend et al. (1992), with modifications as described in Phend et al. (1995) and Valtschanoff et al. (1999). Briefly, after treatment with $4 \%$ p-phenylenediamine in Tris-buffered saline (TBS) containing detergent (TBS/D; 0.05 M Tris, pH 7.6, dissolved in normal saline, with $0.005 \%$ Tergitol NP-10) for $1 \mathrm{~min}$, grids were rinsed and incubated overnight at $37^{\circ} \mathrm{C}$ in primary antibody $(1: 500-1: 1000)$, rinsed in TBS/D, $\mathrm{pH} 7.6$,

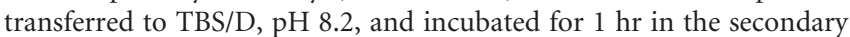
antibody. For descriptive observation, goat anti-rabbit IgG conjugated to $18 \mathrm{~nm}$ gold particles (Jackson ImmunoResearch, West Grove, PA) (1:25 in TBS/D, pH 8.2) was used as a secondary antibody. For quantitative study we used a primary antibody concentration of 1:1000 and $10 \mathrm{~nm}$ gold particles conjugated to the $\mathrm{F}(\mathrm{ab}) 2$ fragment of IgG (BB International, from Ted Pella, Redding, CA). Immunolabeled grids were rinsed and then counterstained with uranyl acetate and Sato's lead. To study colocalization of ErbB4 and PSD-95 on the same thin section, the two antigens were labeled with two sizes of immunogold using the same protocol as for single labeling [rabbit anti-ErbB4, 1:500 with $18 \mathrm{~nm} \mathrm{sec-}$ ondary (Jackson ImmunoResearch), and mouse anti-PSD-95 1:100 (Transduction Labs, Lexington, KY) with $10 \mathrm{~nm}$ secondary from BB International]

Grids were examined on a Tecnai 12 electron microscope (Phillips) at $80 \mathrm{kV}$ accelerating voltage. For quantitative study, digital images were acquired with a Gatan CCD at 30,000 $\times$ magnification and stored as .tiff files. Measurements of positions of gold particles coding for ErbB4 were made interactively with NIH image software. To define the position of each particle in terms of its axodendritic distance from the postsynaptic membrane, a line was drawn along the outer leaflet of the postsynaptic membrane. Axodendritic distance was defined by a perpendicular from this line to the center of each gold particle. To graph labeling density, these distances were put into $5 \mathrm{~nm}$ axodendritic bins. To reduce sampling noise, binned data were smoothed with a five-channel binomial algorithm, using Cricket Graph III (Computer Associates, Islandia, NY). To define the position of each particle in terms of its lateral position, two perpendicular lines were drawn at each edge of the PSD, and the distance from each of these along the postsynaptic membrane to the perpendicular projection of each particle onto the membrane was measured. If these two distances are $a$ and $b$, the total length of the PSD is $(a+b)$. We defined the normalized tangential position $L=$ absolute value $((a-$ $b) /(a+b))$. Thus, if the particle lies at the center of the PSD, $L=0$; if it lies at one edge, $L=1.0$ (Kharazia and Weinberg, 1999; Naisbitt et al., 2000).

\section{Cell culture and transfection}

Primary cortical neurons were cultured as described previously (Banker and Cowan, 1977). In brief, cortex was dissected from embryonic day 18 (E18) rats and incubated with $2.5 \%$ trypsin at $37^{\circ} \mathrm{C}$ for $15 \mathrm{~min}$. Cortical neurons were grown in neural basal medium (Invitrogen, Gaithersburg, $\mathrm{MD}$ ) with B27 (Invitrogen) for 10-12 d. Neurons were seeded on 60mm-diameter dishes at a density of $3.0 \times 10^{6}$ cells per dish and maintained in a humidified incubator with $5 \% \mathrm{CO}_{2}$ at $37^{\circ} \mathrm{C}$.

Human embryonic kidney (HEK) 293 cells were maintained in DMEM supplemented with $10 \%$ fetal bovine serum. HEK 293 cells were transfected using a standard calcium phosphate technique (Sambrook et al., 1989). Briefly, cells were split to $50-70 \%$ confluency before the day of transfection. Plasmid (5-10 $\mu \mathrm{g})$ was resuspended in $500 \mu \mathrm{l}$ of $\mathrm{H}_{2} \mathrm{O}$ containing $0.25 \mathrm{mM} \mathrm{CaCl}_{2}$ and then mixed drop-wise with $500 \mu \mathrm{l}$ of HEBS buffer (55 mm HEPES, $270 \mathrm{~mm} \mathrm{NaCl}$, and $1.5 \mathrm{~mm} \mathrm{NaHPO}_{4}$, pH 7.0). The DNA was precipitated for $20 \mathrm{~min}$ at room temperature. The mixture was added evenly over culture dishes. Two days after transfection, cells were washed with PBS and then treated with the lysis buffer $(1 \mathrm{ml} / 100 \mathrm{~mm}$ plate) containing $20 \mathrm{~mm}$ sodium phosphate, $\mathrm{pH} 7.4,50 \mathrm{~mm}$ sodium fluoride, $40 \mathrm{~mm}$ sodium pyrophosphate, $1 \%$ Triton X-100, 2 mm sodium vanadate, $10 \mathrm{~mm} p$-nitrophenylphosphate, and protease inhibitors including $10 \mu \mathrm{g} / \mathrm{ml}$ aprotinin, $1 \mu \mathrm{g} / \mathrm{ml}$ pepstatin $\mathrm{A}$, and $1 \mu \mathrm{g} / \mathrm{ml}$ leupeptin (Si et al., 1996). Lysed cells were scraped from dishes and incubated on ice for $30 \mathrm{~min}$ and centrifuged at $13,000 \times g$ for $10 \mathrm{~min}$ at $4^{\circ} \mathrm{C}$. The supernatant was designated as cell lysate.

\section{Lipid rafts preparation}

Isolation of lipid rafts from the brain. Lipid rafts were prepared as described previously (Bruckner et al., 1999). Briefly, brains (1 gm) of adult rats $(200-400 \mathrm{gm})$ were homogenized in $3 \mathrm{ml}$ of buffer A containing (in mM): 20 Tris/HCl, pH 7.4, $50 \mathrm{NaCl}, 250$ sucrose, 1 DTT, 0.5 sodium vanadate, 1 PMSF, $10 \mu \mathrm{g} / \mathrm{ml}$ aprotinin, $1 \mu \mathrm{g} / \mathrm{ml}$ pepstatin A, and $1 \mu \mathrm{g} / \mathrm{ml}$ leupeptin with a glass-Teflon homogenizer. After passing through a $22 \mathrm{ga}$ needle three times, homogenates were spun at $960 \times g$ for $10 \mathrm{~min}$ at $4^{\circ} \mathrm{C}$. The supernatant was collected, whereas the pellets, which may contain Triton-insoluble cytoskeleton, were discarded. The pellet was resuspended in $1 \mathrm{ml}$ of buffer $\mathrm{A}$, which was passed through a 22 ga needle three times and spun as above. The two supernatants were combined and 
mixed with OptiPrep (final concentration of $35 \%, 5 \mathrm{ml}$ ) and placed at the bottom of SW41 centrifugation tubes. On the top of the sample were three more layers of OptiPrep (30, 20, and 5\% in buffer A, $2.5 \mathrm{ml}$ each). The sample was subjected to centrifugation at $200,000 \times g$ for $3 \mathrm{hr}$ at $4^{\circ} \mathrm{C}$. The fraction $(300 \mu \mathrm{l})$ in the 5-20\% interface was incubated with $200 \mu \mathrm{l}$ of buffer A containing $0.25 \%$ Triton X-100 at $4^{\circ} \mathrm{C}$ for $20 \mathrm{~min}$. The solubilized preparation was mixed with OptiPrep (final concentration of $35 \%$, $1 \mathrm{ml}$ ) and placed at the bottom of SW60 tubes. On the top of the sample were one layer of OptiPrep (30\% in buffer A with 0.1\% Triton X-100, 2.5 $\mathrm{ml}$ ) and another layer of buffer A with $0.1 \%$ Triton X-100 (0.5 ml). After centrifugation at $200,000 \times g$ for $4 \mathrm{hr}$ at $4^{\circ} \mathrm{C}$, eight fractions (each $0.5 \mathrm{ml}$ ) were collected from top to bottom. The top fraction (fraction 1) contained caveolin and was designated the lipid rafts, and the bottom fraction (fraction 8) was designated as the Triton-soluble fraction.

Isolation of lipid rafts from cultured neurons. Cultured neurons from a $60 \mathrm{~mm}$ dish, either control or treated, were collected in PBS and resuspended in $150 \mu$ l buffer B containing (in $\mathrm{mm}$ ): 50 Tris/ $\mathrm{HCl}, \mathrm{pH} 7.4,150$ $\mathrm{NaCl}, 5$ EDTA, $0.1 \%$ Triton X-100, 0.5 sodium vanadate, 1 PMSF, 10 $\mu \mathrm{g} / \mathrm{ml}$ aprotinin, $1 \mu \mathrm{g} / \mathrm{ml}$ pepstatin $\mathrm{A}$, and $1 \mu \mathrm{g} / \mathrm{ml}$ leupeptin. Cells were homogenized by passing them through a 27 ga needle three times. Homogenates were mixed with OptiPrep (final concentration of 35\%, 360 $\mu \mathrm{l})$, loaded at the bottom of an SW60 centrifuge tube, and overlaid with $3.5 \mathrm{ml}$ of $30 \%$ OptiPrep in buffer B and $0.5 \mathrm{ml}$ of buffer B. The sample was centrifuged at $200,000 \times g$ for $4 \mathrm{hr}$ at $4^{\circ} \mathrm{C}$. Six fractions $(0.7 \mathrm{ml}$ each $)$ or five fractions $(0.84 \mathrm{ml}$ each) were collected from top to bottom. The top fraction contained caveolin and designated the lipid rafts, whereas the bottom fraction was designated as the soluble fraction. Similar results were obtained when the Triton X-100 concentration in buffer B was increased to $0.5 \%$.

\section{Isolation of Triton-insoluble fraction from HEK 293 cells}

HEK 293 cells or cultured neurons were rinsed with PBS and lysed in buffer C containing 1\% Triton X-100, 10\% glycerol, 20 mM HEPES, pH $7.2,100 \mathrm{~mm} \mathrm{NaCl}, 1 \mathrm{~mm}$ PMSF, $10 \mu \mathrm{g} / \mathrm{ml}$ aprotinin, $1 \mu \mathrm{g} / \mathrm{ml}$ pepstatin A, $1 \mu \mathrm{g} / \mathrm{ml}$ leupeptin, and $1 \mathrm{~mm}$ sodium vanadate. The lysates were centrifuged at $16,000 \times g$ for $15 \mathrm{~min}$ at $4^{\circ} \mathrm{C}$. The supernatant was designated as the Triton-soluble fraction. The pellet was washed with PBS, resuspended, and dissolved by sonication in buffer $\mathrm{C}$ containing $0.5 \%$ SDS. A brief centrifugation at $16,000 \times g$ for $10 \mathrm{~min}$ at $4^{\circ} \mathrm{C}$ was necessary to isolate the insoluble pellet. The supernatant was designated as the Tritoninsoluble fraction.

Preparation of PSD fraction and isolation of lipid rafts from PSDs PSDs were purified from brain of adult rats as described previously (Blackstone et al., 1992). In brief, adult rat brains were homogenized in buffered sucrose (0.32 $\mathrm{m}$ sucrose and $4 \mathrm{~mm}$ HEPES/NaOH, $\mathrm{pH}$ 7.4) with a glass-Teflon homogenizer. The homogenate was centrifuged at $800 \times$ $g$ for $10 \mathrm{~min}$. The supernatant (S1) was centrifuged at $9000 \times g$ for 15 min, yielding P2 (the crude synaptosomal fraction) and S2. The P2 fraction was resuspended in the homogenizing buffer and subjected to another centrifugation at $10,000 \times g$ for $15 \mathrm{~min}$. The resulting pellet was lysed by hypo-osmotic shock in water, rapidly adjusted to $\mathrm{pH} 7.4$ with 1 mM HEPES/NaOH, and stirred on ice for $30 \mathrm{~min}$. The resuspended pellet was then centrifuged at $25,000 \times g$ for $20 \mathrm{~min}$, yielding the P3 fraction. The P3 fraction was resuspended in $0.25 \mathrm{M}$ buffered sucrose, layered onto a discontinuous sucrose gradient containing 0.8/1.0/1.2 $\mathrm{M}$ sucrose, and centrifuged for $2 \mathrm{hr}$ at $65,000 \times g$. The gradient yielded a synaptosomal plasma membrane (SPM) fraction at the 1.0/1.2 M sucrose interface. The SPM fraction was solubilized with $0.4 \%$ Triton X-100 in 0.5 mM HEPES/ $\mathrm{NaOH}, \mathrm{pH} 7.4$, and subjected to centrifugation at 25,000 $\times g$ for $20 \mathrm{~min}$, yielding an insoluble PSD fraction.

To isolate the lipid raft fraction from PSD, the PSD fraction was resuspended with $150 \mu \mathrm{l}$ of buffer B on ice for $20 \mathrm{~min}$ and then mixed with OptiPrep (final concentration of 35\%,360 $\mu \mathrm{l}$ ), loaded at the bottom of an SW60 centrifuge tube, and overlaid with $3.5 \mathrm{ml}$ of 30\% OptiPrep in buffer B and $0.5 \mathrm{ml}$ of buffer B. The sample was centrifuged at 200,000 $\times$ $g$ for $4 \mathrm{hr}$ at $4^{\circ} \mathrm{C}$. Eight fractions $(0.5 \mathrm{ml}$ each $)$ were collected from top to bottom.

\section{Immunoprecipitation and immunoblotting}

Soluble or rafts fractions ( $\sim 400 \mu \mathrm{g}$ of protein) were incubated directly with or without the indicated antibodies for $1 \mathrm{hr}$ at $4^{\circ} \mathrm{C}$. They were then incubated with protein $\mathrm{A}$-agarose beads overnight at $4^{\circ} \mathrm{C}$ on a rotating platform. After centrifugation, beads were washed four to five times with the lysis buffer. Bound proteins were eluted with SDS sample buffer and subjected to SDS-PAGE. Proteins resolved on SDS-PAGE were transferred to nitrocellulose membranes (Schleicher and Schuell, Keene, NH). Nitrocellulose blots were incubated at room temperature for $1 \mathrm{hr}$ in TBS with $0.1 \%$ Tween and $5 \%$ milk, followed by an incubation with $1 \%$ milk with indicated antibodies. For blotting with anti-phosphotyrosine antibody, nitrocellulose blots were incubated with $3 \%$ bovine serum albumin in the blocking buffer and $1 \%$ bovine serum albumin in the blotting buffer. After washing three times for 15 min each with TBS with $0.1 \%$ Tween, the blots were incubated with horseradish peroxidaseconjugated donkey anti-mouse or anti-rabbit IgG (Amersham Biosciences, Piscataway, NJ) followed by another wash. Immunoreactive bands were visualized using enhanced chemiluminescence substrate (Pierce, Rockford, IL). All immunoblotting was repeated at least three times. In some experiments, after visualizing an immunoreactive protein, the nitrocellulose filter was incubated in a buffer containing 62.5 mu Tris/ $\mathrm{HCl}, \mathrm{pH} 6.7,100 \mathrm{~mm} \beta$-mercaptoethanol, and $2 \%$ SDS at $50^{\circ} \mathrm{C}$ for $30 \mathrm{~min}$, washed with TBS with $0.1 \%$ Tween at room temperature for $1 \mathrm{hr}$, and reblotted with different antibodies. For quantitative analysis, autoradiographic films were scanned with a Personal Densitometer (Molecular Dynamics, Sunnyvale, CA), and the captured image was analyzed with NIH Image software.

\section{Electrophysiology}

Methods for preparing hippocampal slices and recording extracellular field EPSPs (fEPSPs) have been described in detail previously ( $\mathrm{Lu}$ et al., 1998). Briefly, hippocampal slices were prepared from 3- to 4-week-old male Sprague Dawley rats and placed in a holding chamber for at least 1 $\mathrm{hr}$ before recording. A single slice $(400 \mu \mathrm{m})$ was then transferred to a recording chamber and superfused with artificial CSF (ACSF) (at $2 \mathrm{ml} /$ min) composed of (in mM): $124 \mathrm{NaCl}, 3 \mathrm{KCl}, 1.25 \mathrm{NaH}_{2} \mathrm{PO}_{4}, 2 \mathrm{MgCl}_{2}, 10$ D-glucose, $20 \mathrm{NaHCO}_{3}$, and $2 \mathrm{CaCl}_{2}$ saturated with $95 \% \mathrm{O}_{2}$ (balance $5 \%$ $\mathrm{CO}_{2}$ ) at $30 \pm 2^{\circ} \mathrm{C}, \mathrm{pH} 7.40(310-320 \mathrm{mOsm})$. ACSF was supplemented as indicated with NRG ( $2 \mathrm{nM})$, which was stored as $100,000 \times$ single-use aliquots in water at $-80^{\circ} \mathrm{C}$. ACSF was also supplemented as indicated with methyl- $\beta$-cyclodextrin (MCD) $(0.1 \mathrm{~mm})$, which was made fresh immediately before the experiment. fEPSPs were evoked using bipolar tungsten electrodes located $\sim 50 \mu \mathrm{m}$ from the cell body layer in CA1 and were recorded using glass micropipettes filled with ACSF placed in the stratum radiatum $60-80 \mu \mathrm{m}$ from the cell body layer. Test stimuli were at $0.1 \mathrm{~Hz}$, and the stimulus intensity was set to $25 \%$ of that which produced maximum synaptic responses. Tetanic stimulation consisted of two trains of $100 \mathrm{~Hz}$ stimuli, each lasting $500 \mathrm{msec}$, at an intertrain interval of $10 \mathrm{sec}$. fEPSP slope was calculated as the slope of the rising phase between 10 and $60 \%$ of the peak of the response. Data were recorded using an Axoclamp 1D amplifier and sampled at $10 \mathrm{KHz}$ by computer.

\section{Animal welfare}

All the procedures were strictly in accord with protocols approved by the Institutional Animal Care and Use Committee of the University of Alabama at Birmingham. Animals were killed in accord with recommendations of the Panel on Euthanasia of the American Veterinary Medical Association.

\section{Results}

\section{Localization of ErbB4 in brain PSDs}

ErbB4 is expressed in all areas of adult rat brain (Gerecke et al., 2001). ErbB4 has been shown to be present in biochemical PSD fractions from brain and to colocalize with synaptophysin in cultured hippocampal neurons at the light microscopic level (Garcia et al., 2000; Huang et al., 2000), but it was unclear whether ErbB4 is specifically localized at postsynaptic membranes of CNS synapses in vivo. To address this issue, we performed postembedding 


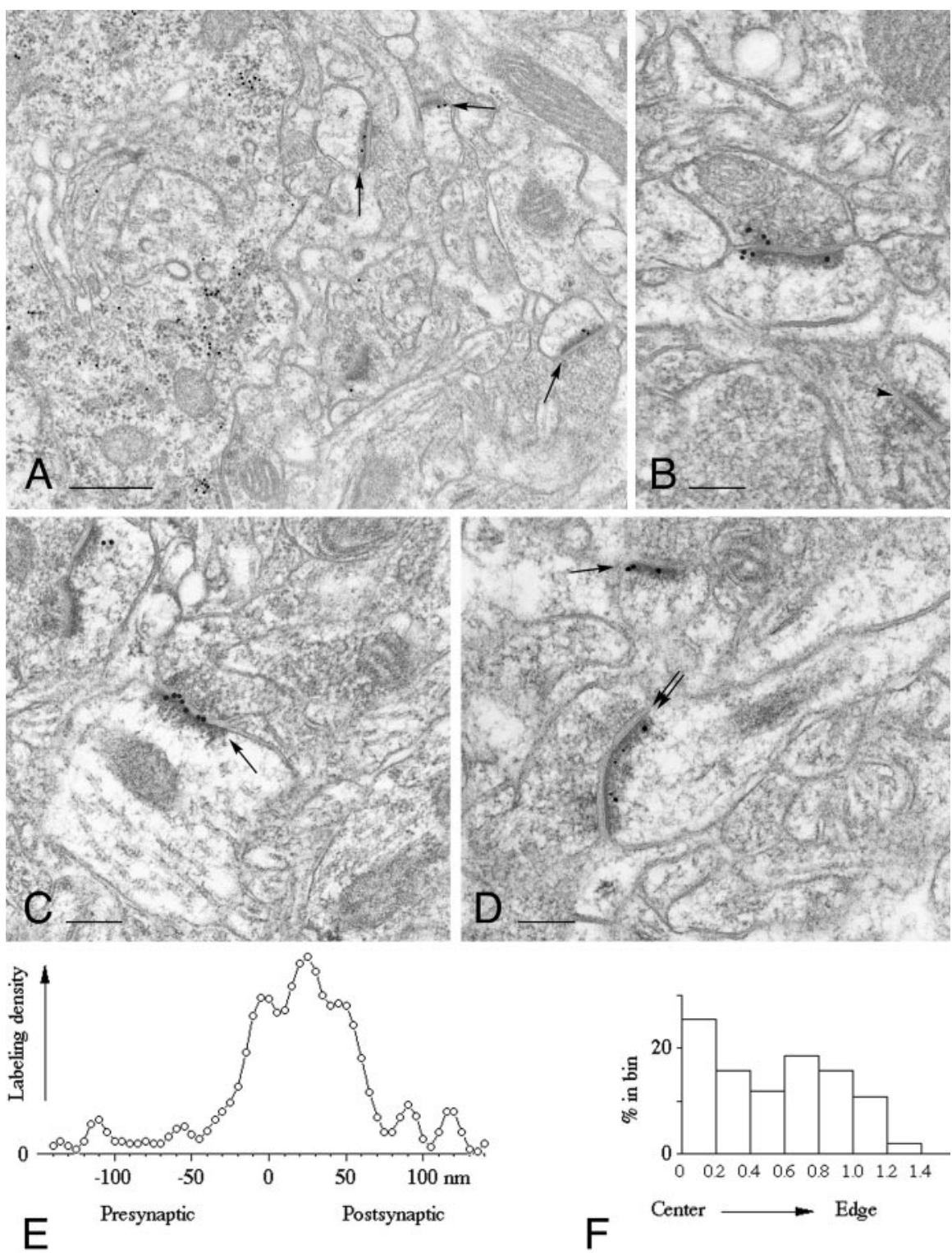

Figure 1. Immuno-electron microscopic localization of ErbB4 in rat somatosensory cortex. $A-C$, Immunogold labeling for ErbB4 was associated primarily with asymmetric synapses (arrows). In neuronal perikarya (a neuronal soma occupies the left half of this photograph), the rough endoplasmic reticulum was also labeled. In asymmetric synapses onto both spines $(A)$ and shafts $(C)$, labeling was mainly over the PSD; in some synapses $(B)$, some gold particles were also presynaptic. Not all synapses were labeled ( $B$, arrowhead). D, Double labeling for ErbB4 (large gold particles) and PSD-95 (small gold particles) revealed double-labeled synapses (double arrow) as well as single-labeled synapses (arrow). E, F, Quantitative analysis of the distribution of ErbB4 immunogold particles at synapses; data include 99 gold particles from 53 asymmetric synapses, with clearly defined synaptic membranes and at least $1 \mathrm{gold}$ particle within $\pm 100 \mathrm{~nm}$ of the postsynaptic membrane. E, Distribution along the axodendritic axis. Abscissa represents distance from the center of each gold particle to the outer leaflet of the postsynaptic membrane; ordinate is labeling density (arbitrary units). Labeling density is highest over the PSD. Data ( $5 \mathrm{~nm}$ bins) were smoothed using a five-point weighted running average (see Materials and Methods). F, Labeling is fairly uniformly distributed along the length of the synapse. Lateral position is normalized; the center of the synapse corresponds to 0 , and the edge corresponds to 1.0 (see Materials and Methods). For $E$, all particles with normalized lateral position $<1.1$ were included; for $F$, all particles with axodendritic position less than $\pm 100 \mathrm{~nm}$ were included. Scale bars: $A, 500 \mathrm{~nm} ; B-D, 200 \mathrm{~nm}$.

immunogold electron microscopy on material from three rats. In tissue blocks cut from layers I-III of somatic sensory cortex, a large fraction of gold particles coding for ErbB4 was associated with asymmetric synapses likely to use glutamate as neurotransmitter (Fig. $1 A-C$ ). Results were similar for each of the three rats. Synaptic labeling was predominantly over the PSD and the postsynaptic membrane; labeling was significantly weaker over nonsynaptic plasma membranes (Fig. $1 A-C$ ). Some labeling was found over synaptic vesicles, inside dendrites and dendritic spines, and on rough endoplasmic reticulum in the cell body (Fig. 1A). The labeling appeared to be specific in that immunolabeling could be blocked with peptide preabsorption. To explore a possible relationship between ErbB4 and the adaptor protein PSD-95, we performed double labeling, using two different sizes of colloidal gold as secondary antibodies. Technical obstacles prevented quantitative analysis of the double-labeling data, but we found that many synapses were immunolabeled for both ErbB4 and PSD-95 (Fig. 1D).

We performed several controls to verify staining specificity. In experiments in which primary antibody was omitted, immunogold staining was virtually completely eliminated. If normal rabbit serum was substituted for primary antibody, sparse gold particles were seen over all tissue compartments, showing no obvious association with synapses. Finally, we examined material processed with primary antibody that had first been incubated with the same antigenic peptide used to prepare the antibody (peptide concentration, $100-200 \mu \mathrm{g} / \mathrm{ml}$ ). Some immunogold labeling remained over cytoplasmic compartments, but staining associated with synapses was virtually eliminated. On the basis of these controls, we conclude that the synaptic staining observed represented ErbB4 protein.

To analyze the labeling associated with synapses in more detail, we took micrographs of random fields selected to contain at least one asymmetric synapse with sharp membranes (implying a plane of section approximately normal to the plane of the synapse), for which at least one gold particle lay within $\pm 100 \mathrm{~nm}$ of the postsynaptic membrane. Ten micrographs from two sections from each of the three rats (for a total of 60 micrographs) were analyzed. We measured the axodendritic and tangential positions of 99 gold particles from 53 synapses that met the above selection criteria, with respect to the postsynaptic membrane. To confirm that labeling was associated mainly with the PSD, we counted gold particles within a $45 \mathrm{~nm}$ strip parallel to the membrane and laterally bounded by the two edges of the active zone, from $2.5 \mathrm{~nm}$ outside the postsynaptic plasma membrane to $42.5 \mathrm{~nm}$ cytoplasmic to it (encompassing the bulk of the PSD), and compared this count with the number of gold particles lying over a corresponding $45 \mathrm{~nm}$ strip from $2.5 \mathrm{~nm}$ outside the postsynaptic membrane to $47.5 \mathrm{~nm}$ outside the membrane (encompassing the synaptic cleft and presynaptic active zone). We found 47 particles associated with the PSD, compared with 23 particles associated with the cleft and presynaptic active 
zone $\left(\chi^{2}=9.33 ; p<0.01 ; \mathrm{df}=1\right)$. These data show that ErbB4 is selectively enriched in the morphological PSD.

To analyze the distribution of synapse-related antigen in more detail, we computed histograms of axodendritic and tangential positions for the measured particles. Although labeling efficiency varied somewhat from animal to animal, spatial distributions were similar for each of the three animals; to get a larger sample, we combined the data. Particle density in the axodendritic axis exhibited a broad peak at $\sim 25 \mathrm{~nm}$ inside the postsynaptic membrane, diminishing markedly within $75 \mathrm{~nm}$ into the postsynaptic profile, which for most synapses encompasses the PSD and the subsynaptic web (Fig. $1 E$ ). Considering the inherent $\sim 25 \mathrm{~nm}$ localization error of individual particles associated with immunogold techniques (Kellenberger, 1991), these data suggest that ErbB4 is highly concentrated within a thin lamina just beneath the synaptic plasma membrane. The lateral distribution of particle density was rather uniform along the synaptic specialization (Fig. $1 F$ ).

Examination of randomly selected asymmetric synapses of material from the two animals with the best ultrastructure revealed that 415 of 1071 (38.7\%) asymmetric synapses were immunopositive, as defined by the presence of a gold particle within $25 \mathrm{~nm}$ of the postsynaptic membrane or PSD. Immunogold involves inevitable stochastic variability, related to random factors like the exact location and orientation of antigen molecules in relation to the surface of the plastic section. To explore whether this variability might have led to a sizeable population of false negatives, we made a new set of particle measurements from the same material used to count the 1071 synapses. We excluded all particles $>100 \mathrm{~nm}$ from the postsynaptic membrane or lying outside the lateral borders of the active zone, plotted the distribution of particle counts/synapse, and compared this with the theoretical distribution of a Poisson distribution with the same mean $(\lambda=2.83)$. As shown in Figure 2, the measured distribution fits the theoretical Poisson distribution quite well, suggesting that most of the immunonegative synaptic profiles indeed lacked antigen. However, the measured distribution shows an excess in the $n=1$ bin, suggesting a subpopulation of weakly positive synapses; therefore, we cannot exclude the possibility that many of the apparently immunonegative profiles contained ErbB4, but at levels too low to detect with our methods. To examine the issue of synaptic heterogeneity further, we made a scatterplot of snynaptic labeling/synapse as a function of active zone length (data not shown). Although the scatterplot was noisy, linear regression revealed a significant negative correlation (slope $=$ $-0.28 ; p<0.01$ ). We therefore conclude that ErbB4 concentrates preferentially at the PSD of relatively small asymmetric synapses, suggested by previous work to contain relatively high concentrations of NMDA receptors and low concentrations of AMPA receptors (Kharazia and Weinberg, 1999).

\section{Presence of ErbB4 in lipid raft fractions in the brain}

To investigate whether ErbB4 associates with lipid rafts, we isolated membranes from adult rat brain, from which we prepared lipid raft fractions (see Materials and Methods). After the final centrifugation, eight fractions of membrane proteins were collected from the top and subjected to SDS-PAGE followed by immunoblotting using anti-ErbB4 antibodies. As shown in Figure $3 A$, when equal volumes $(40 \mu \mathrm{l})$ of different fractions were analyzed, some ErbB4 was found in the top fraction of the discontinuous gradient (fraction 1). Caveolin, the lipid raft marker protein, copurified with ErbB4 in the lightest fraction. Unlike caveolin, however, which was found only in top fractions, a sig-

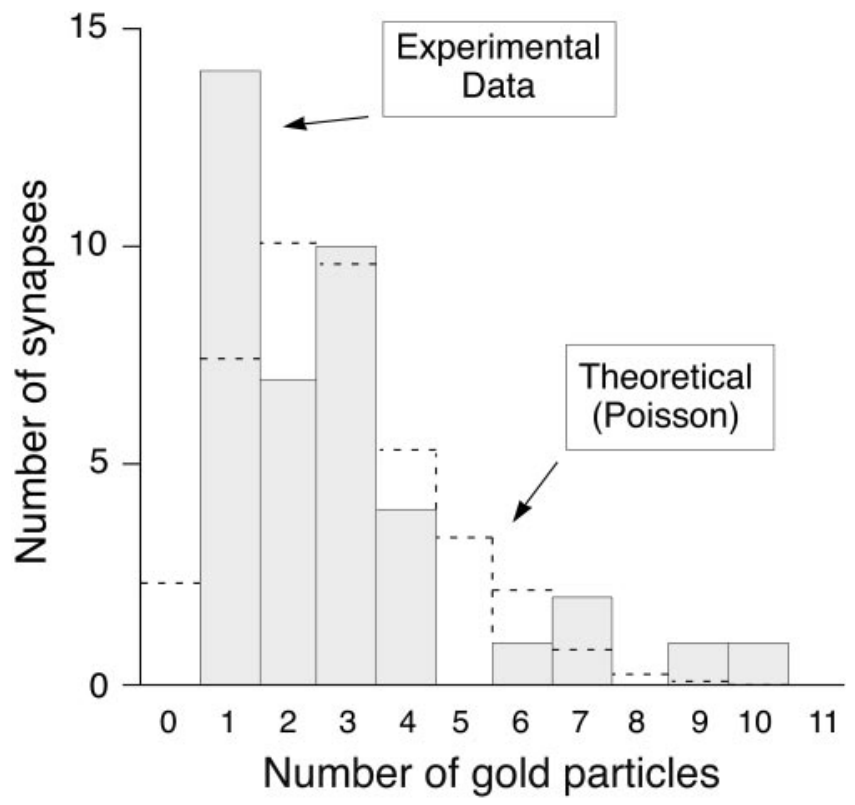

Figure 2. Synaptic labeling fits a Poisson distribution. Gray bars show numbers of synapses with different numbers of gold particles, from a total of 40 synapses analyzed. The measured value for zero is 0 by definition, because immunonegative synapses were excluded from analysis. Data are well fit by a Poisson distribution with the same mean as the mean number of particles/synapse measured in the experimental data (dashed lines). That the Poisson curve predicts a small number of immunonegative synapses suggests that most of the numerous immunonegative synapses observed (at least half of the asymmetric synapses in these grids) lacked ErbB4 protein. However, the relatively numerous synapses with only a single particle (compared with the Poisson distribution) raise the possibility that a subpopulation of synapses may express ErbB4 at very low levels.

nificant amount of ErbB4 was in Triton-soluble fractions (fractions 6, 7, and 8).

Quantitative analysis showed most of the proteins were present in the top and bottom fractions (Fig. $3 B$ ). These results suggest that ErbB4 in the brain exists in both lipid raft and nonraft microdomains. To quantify the amount of ErbB4 in the raft fraction, we compared ErbB4 signals in each lane with those in the standard curve showing percentages of the input. Quantitative analysis revealed that the top two light fractions, where caveolin was enriched, contained at least $40 \%$ of total ErbB4 (Fig. $3 C$ ). Thus, $\sim 40 \%$ of ErbB 4 in the brain is associated with lipid rafts. This distribution pattern did not generalize to all types of receptor; for example, the transferrin receptor was found primarily in the high-density fractions (Fig. 3D).

PSD-95 is a major component of the PSD (Kennedy, 1997; Craven and Bredt, 1998; Garner et al., 2000; Sheng and Sala, 2001), and the $C$ terminus of ErbB4 interacts with the first two PDZ domains of PSD-95 (Garcia et al., 2000; Huang et al., 2000). To determine whether PSD-95 and its family members were localized to lipid rafts in the brain, fractions generated by discontinuous gradient centrifugation were immunoblotted with specific antibodies. Like ErbB4, PSD-95, SAP97, and SAP102 were found in lipid rafts (Fig. 3D). By comparing with a standard blot (Fig. $3 A$ ), we determined that $\sim 60 \%$ of total PSD-95 in the brain was associated with lipid rafts (Fig. 3C).

\section{NRG induces translocation of ErbB4 and its associated signaling proteins into lipid raft fractions}

When cultured cortical neurons were subjected to lipid raft isolation, most of the protein was present in the top and bottom 
A

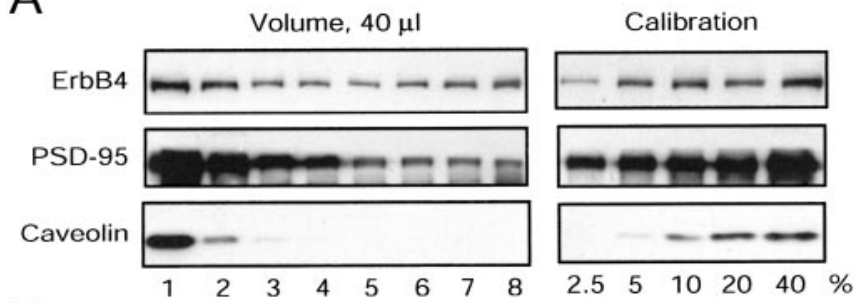

B

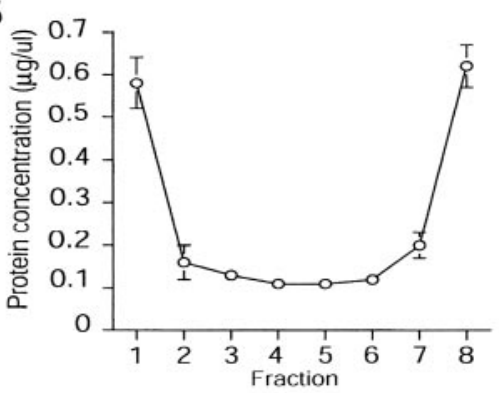

C

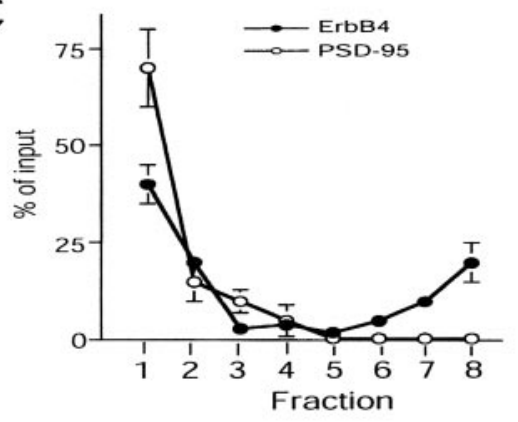

$\mathrm{D}$

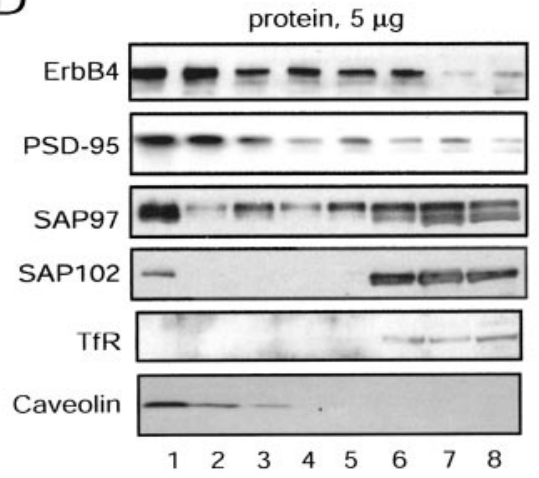

Figure 3. ErbB4 and PSD-95 associate with lipid rafts in the brain. $A$, ErbB4 in lipid rafts. Membranes of rat brains were subjected to OptiPrep gradient centrifugation after incubation with Triton $X-100$. Gradient fractions were collected from the top to the bottom and subjected to SDS-PAGE, followed by immunoblotting using the indicated antibodies. Equal volumes $(40 \mu \mathrm{l})$ were loaded onto each lane. The right panel is a standard-curve blot showing various percentages of the input that were subjected to lipid raft purification. Representative blots from three independent experiments with similar results are shown. $B$, Protein concentration in fractions in $A$. C, Quantitative analyses of data in $A$ (mean $\pm \mathrm{SEM} ; n=3$ ). ErbB4 in lipid rafts (the top two fractions in which caveolin is enriched) accounts for $40 \%$ of the total amount in membranes, whereas PSD- 95 accounts for $60 \%$. D, Distribution of PSD-95 family members and TfR in membrane fractions. Equal amounts of proteins $(5 \mu \mathrm{g})$ were loaded onto each lane. Experiments were done as in $A$, except that the indicated antibodies against PDZ domain-containing proteins were used. Representative blots from three independent experiments with similar results are shown.

fractions (Fig. $4 B$ ). Interestingly, ErbB4 was present, but not enriched, in lipid rafts in naive cultured cortical neurons (Fig. $4 \mathrm{~A}$, fraction 1). The differential distribution of ErbB4 in the brain and in cultured neurons suggests that ErbB4 partitioning in lipid rafts may be a regulated event. To test this hypothesis, we investigated whether NRG stimulation of ErbB4 affects its distribution in the plasma membrane in cultured cortical neurons. Indeed, the amount of ErbB4 in lipid rafts increased dramatically after NRG stimulation (Fig. 4A). The shift appeared to peak at $15 \mathrm{~min}$ after NRG stimulation, with ErbB4 localized mainly in the top two fractions (Fig. 4C,D). At $30 \mathrm{~min}$, the amount of ErbB4 in lipid rafts started to decrease, shifting to the third and fourth fractions. In contrast, NRG induced no apparent shift of the NMDA receptor subunit 1 (NR1) distribution (Fig. 4C,D), suggesting that NRG did not nonspecifically recruit membrane proteins to lipid rafts.

On NRG stimulation, the activated ErbB4 becomes phosphorylated on tyrosine (Cohen et al., 1996; Huang et al., 2000; Sweeney et al., 2000). To investigate whether ErbB4 in lipid rafts is activated, we used the tyrosine phosphorylation of ErbB4 as a surrogate measure. We analyzed ErbB4 tyrosine phosphorylation in detergent-soluble and insoluble fractions by immunoblotting with anti-phosphotyrosine antibodies. The amounts of protein used for SDS-PAGE were adjusted so that equal amounts of ErbB4 were in the lipid raft and soluble fractions in control and NRG-treated neurons (Fig. $4 E$, bottom). NRG stimulation increased tyrosine phosphorylation of ErbB4 in lipid rafts (Fig. 4E), suggesting that ErbB4 in lipid rafts is functional. Once activated, the tyrosine-phosphorylated $\mathrm{C}$ terminus of ErbB4 can interact with adaptor proteins including Shc and Grb2 to activate downstream signaling kinases such as Erk (Cohen et al., 1996; Huang et al., 2000; Sweeney et al., 2000). Little, if any, Shc was found in lipid rafts of naive neurons, but the amount was increased dramatically after NRG treatment (Fig. $4 F$ ). Grb2 was present in lipid rafts of naive neurons, but the amount of Grb2 in lipid rafts was also increased in response to NRG (Fig. $4 F$ ). The recruitment of cytoplasmic proteins to lipid rafts after NRG stimulation was specific: we found that NRG had no effect on the distribution of the protein Dishevelled (Dvl), a cytosolic protein involved in Wnt, but not NRG, signaling (Boutros and Mlodzik, 1999). Because Grb2 and Shc are known to be recruited to activated ErbB4 (Cohen et al., 1996; Huang et al., 2000; Sweeney et al., 2000), the present results imply that ErbB4 may carry associated signaling molecules into lipid rafts after NRG stimulation.

\section{ErbB4 in the PSD is associated with lipid raft fractions}

Neurotransmitter receptors and various signaling molecules important for neurotransmission and synaptic plasticity, including ErbB4, are concentrated in the PSD (Kennedy, 1997; Ziff, 1997; Sheng and Sala, 2001). To determine whether ErbB4 is distributed in lipid rafts within postsynaptic membranes, we prepared the PSD fraction and subjected it to discontinuous gradient centrifugation to separate lipid raft and non-raft components. We found that within the PSD preparation both ErbB4 and PSD-95 were present almost exclusively in the fractions where caveolin was enriched (Fig. 5A), suggesting that they are tightly associated with lipid rafts in the PSD. To demonstrate that the PSD includes both raft and non-raft components, we stained the SDS-PAGE gel with Coomassie blue (Fig. $5 B$ ). Numerous proteins were observed in both low- and high-density fractions. Thus, the PSD contains both raft and non-raft components, and ErbB4 and PSD-95 are preferentially localized in the lipid raft component.

ErbB4 is localized in the detergent-insoluble fraction in cells coexpressing PSD-95

ErbB4 interacts with PSD-95, which is a scaffold protein in the PSD. Because the N-terminal region of PSD-95 is known to me- 
A

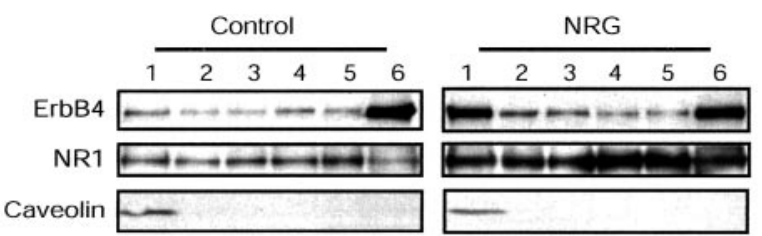

B

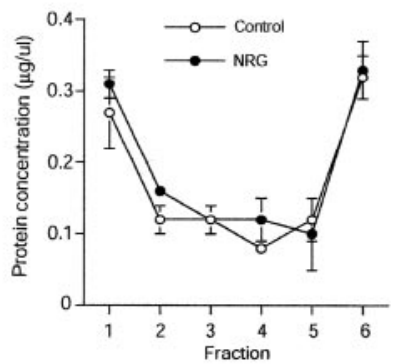

C NRG

$\begin{array}{llllll}(\min ) & 1 & 2 & 3 & 4 & 5\end{array}$
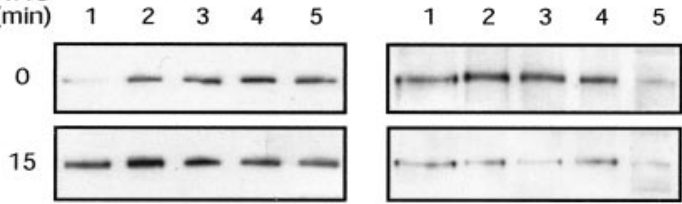

15

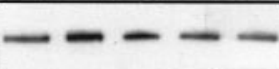

30

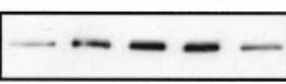

IB: ErbB4

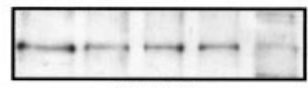

IB: NR1

$\mathrm{D}$

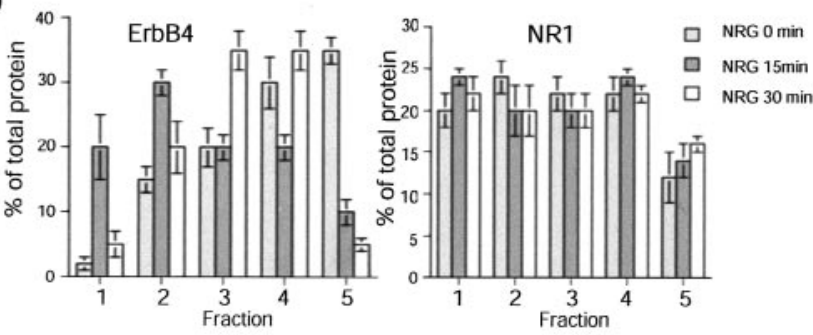

$E$

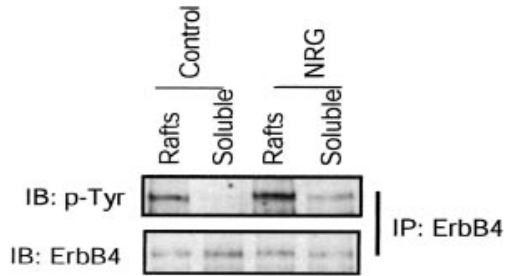

$\mathrm{F}$

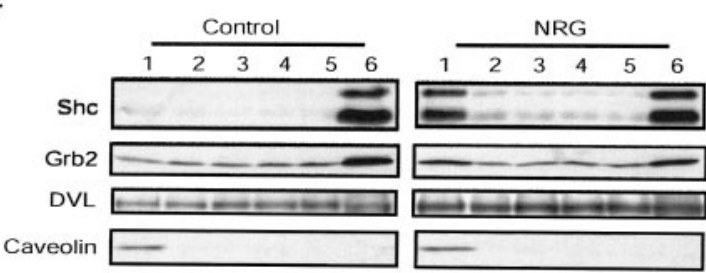

Figure 4. Ligand-dependent recruitment of NRG signaling complexes into lipid rafts in cultured neurons. A, NRG-induced partition of ErbB4, but not NR1, into lipid rafts. Cortical neurons were treated without (left panels) or with (right panels) $10 \mathrm{~nm} \mathrm{NRG} \mathrm{for} 15 \mathrm{~min}$. Cell lysates were subjected to OptiPrep gradient centrifugation after incubation with Triton X-100. In total, six fractions were collected from top to bottom. Aliquots of the fractions $(40 \mu \mathrm{l})$ were resolved on SDS-PAGE and immunoblotted with the indicated antibodies. B, Protein concentration in fractions in $A$. C, Time-dependent ErbB4 partition into lipid rafts. Neurons were treated for different times and lysed. Experiments were done as in $A$, except that the gradient was fractioned into five samples, which were blotted for ErbB4 and NR1. D, Quantitative analyses of data in A (mean $\pm \mathrm{SEM} ; n=3$ ). E, Increased tyrosine phosphorylation of ErbB4 in lipid rafts. Equal amounts of ErbB4 were immunoprecipitated from the raft (top) and soluble (bottom) fractions,
A

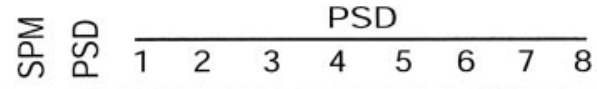

ErbB4

PSD-95

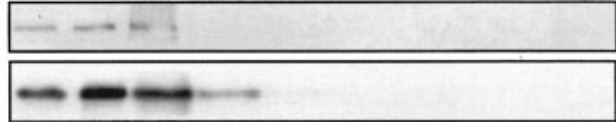

Caveolin

Synaptophysin
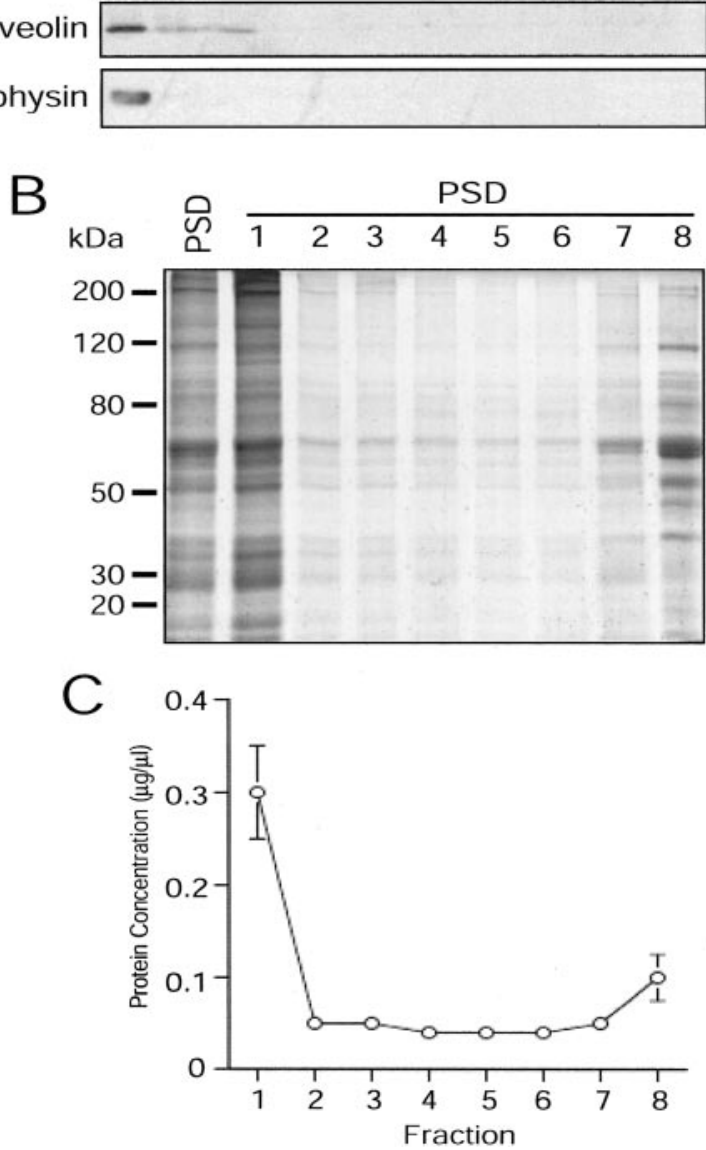

Figure 5. ErbB4 and PSD-95 in the PSD associate with lipid rafts. $A$, Western blotting analyses of ErbB4 and PSD-95 in gradient fractions. Twenty micrograms of SPM, $2 \mu \mathrm{g}$ of PSD, and one-fifth volume of each of the eight fractions were subjected to SDS-PAGE and immunoblotting. PSDs were prepared as described in Materials and Methods. Ten micrograms of the PSD preparation were subjected to OptiPrep gradient centrifugation. Representative blots from three independent experiments with similar results are shown. B, Coomassie-stained SDS-PAGE gel of gradient fractions; equal volumes ( $40 \mu \mathrm{l}$ ) were loaded onto each lane. The PSD contains proteins in both raft and non-raft components. $A$ and $B$ show representative blot or gel from independent experiments with similar results.

diate association with lipid rafts (Perez and Bredt, 1998), we reasoned therefore that the interaction of ErbB4 with PSD-95 may anchor ErbB4 in rafts. To test this hypothesis, we studied the effect of PSD-95 coexpression on ErbB4 distribution in Tritonsoluble and insoluble fractions in HEK 293 cells, because lipid rafts concentrate in the detergent-insoluble fraction (Brown and London, 1998). Transfected ErbB4 was present mainly in the Triton X-100 soluble fraction of HEK 293 cells (Fig. 6A), suggest-

$\leftarrow$

resolved on SDS-PAGE, and immunoblotted with anti-phosphotyrosine antibodies. F, Recruitment of the adapter proteins, Shc and Grb2, and Erk into lipid rafts by NRG. The distribution of Dvl, a cytosolic protein not involved in NRG signaling, was unaffected by NRG. Experiments were performed as in $A . A, C, E$, and $F$ show representative blots from three independent experiments with similar results. 

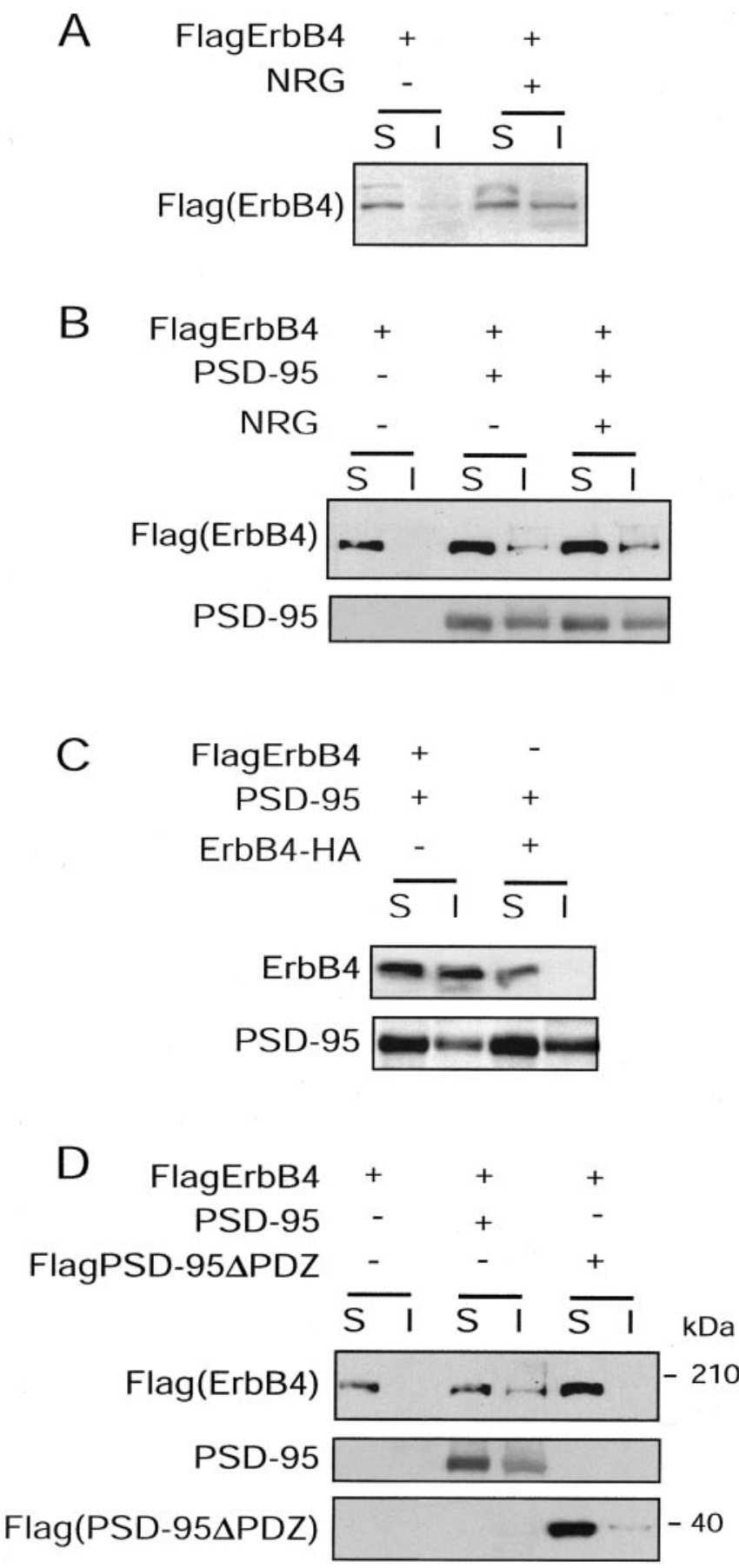

Figure 6. PSD-95 shifts ErbB4 into detergent-insoluble fraction in HEK 293 cells. A, NRG induced partition of ErbB4 into detergent-insoluble fractions. HEK 293 cells were transfected with Flag-tagged ErbB4 and stimulated without or with $10 \mathrm{~nm}$ NRG for $15 \mathrm{~min}$. Triton-soluble and -insoluble fractions, prepared as described in Materials and Methods, were analyzed by SDS-PAGE and immunoblotting. B, Coexpression of PSD-95 shifted ErbB4 into detergentinsoluble fraction. HEK 293 cells were transfected with Flag-ErbB4 alone or together with PSD95. In some experiments, PSD-95 cotransfected cells were stimulated with or without NRG for $15 \mathrm{~min}$. Lysates were fractionated as described in $A$ and probed with the indicated antibodies. C, PSD-95-induced ErbB4 partition into detergent-insoluble fraction was dependent on the intact ErbB4 C terminus. Cells were transfected with PSD-95 and Flag-ErbB4 or ErbB4-HA. ErbB4-HA does not interact with PSD-95 because the Cterminus is masked by the HA epitope (Huang et al., 2000). Lysates were fractionated as described in $A$ and probed with the indicated antibodies. $D$, Dependence of PSD-95-induced ErbB4 partition into detergent-insoluble fraction on PDZ domains of PSD-95. Cells were transfected with Flag-ErbB4 alone or with PSD-95 or PSD-95 $\triangle$ PDZ. Lysates were fractionated as described in $A$ and probed with the indicated antibodies. Representative blots from three independent experiments with similar results are shown. ing that ErbB4 is present mainly in a non-raft fraction in naive HEK 293 cells. As in neurons, NRG stimulation increased the amount of ErbB4 in detergent-insoluble fractions (Fig. 6A). PSD-95, when overexpressed alone, was present in Triton X-100 soluble and insoluble fractions of HEK 293 cells or COS cells (data not shown) (Perez and Bredt, 1998). Coexpression of PSD-95 increased the amount of ErbB4 in the detergentinsoluble fraction (Fig. 6B). Mutation of either the ErbB4 C terminus (ErbB4-HA) or PDZ domains of PSD-95 (FlagPSD95 $\triangle$ PDZ) abolished PSD-95-induced recruitment of ErbB4 into detergent-insoluble fraction (Fig. $6 C, D$ ), suggesting that the presence of ErbB4 in lipid rafts was dependent on the interaction between the two proteins. These results suggest that ErbB4 may be anchored to lipid rafts through binding to the PDZ domains of PSD-95. Note that no further increase of ErbB4 in the detergentinsoluble fraction was observed when PSD-95-transfected cells were stimulated with NRG (Fig. 6B). This result suggests that PSD-95 and NRG may function via a similar mechanism, probably receptor dimerization.

\section{Disruption of lipid rafts inhibits NRG signaling and activation of Erk}

If lipid rafts are important for NRG-induced signaling, disrupting rafts should suppress downstream signaling by ErbB4. To disrupt rafts we used MCD, a water-soluble cyclic oligomer that sequesters cholesterol within its hydrophobic core, thereby depleting cholesterol from the plasma membrane and dispersing lipid rafts (Tansey et al., 2000; Simons and Toomre, 2001). Before investigating the effect of MCD on NRG signaling we determined its effect on neuronal viability. Quantitative analysis using Trypan Blue exclusion indicated that the percentage of dead neurons after MCD treatment $(10 \mathrm{~mm}, 15 \mathrm{~min})$ was the same as control $(\sim 0.3 \%)$. Moreover, there was no difference in morphology between control and MCD-treated neurons (data not shown). Thus, MCD did not affect the viability of cultured neurons under these conditions.

We next determined whether MCD depletes NRG signaling proteins from lipid rafts in the plasma membrane. As shown in Figure 7A, NRG was unable to increase the amount of ErbB4 in lipid rafts of MCD-pretreated neurons. In fact, ErbB4 was present only in Triton-soluble non-raft fractions in these neurons. Similar effects were observed with PSD-95 and Shc (Fig. 7A). To determine whether the ErbB4 partition in lipid rafts is important for NRG signaling, we pretreated neurons with MCD and examined Erk activation in response to NRG. NRG-induced Erk activation was inhibited in MCD-treated neurons (Fig. $7 \mathrm{~B}, C$ ). However, tyrosine phosphorylation of ErbB4 remained unchanged (Fig. 7D), suggesting that MCD could inhibit NRG-induced Erk activation without affecting the kinase activity of ErbB4 or its activation. To ensure that the effect of MCD was caused by disruption of lipid rafts, we studied the effect of filipin, a structurally distinct raft-disrupting agent (Park et al., 1998; Simons and Toomre, 2001). We found that treatment with filipin prevented Erk activation by NRG (Fig. 7E). Together the results with MCD and filipin indicate that lipid rafts are required for NRG signaling.

\section{Lipid raft disruption prevents NRG-induced blockade of LTP induction}

If lipid rafts are required for NRG-ErbB4 signaling, disruption of rafts is predicted to prevent the blockade by NRG of LTP induction at Schaffer collateral-CA1 synapses (Huang et al., 2000). We therefore examined the effect of MCD on this action of NRG in acute slices of rat hippocampus (Fig. $8 A-C$ ). We recorded fEP- 


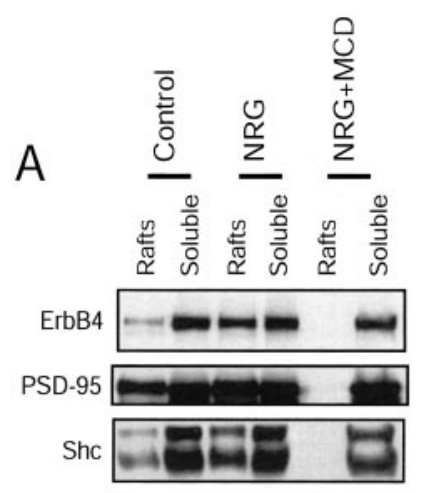

B

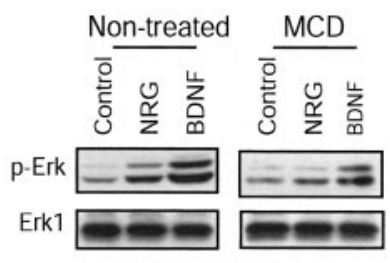

C
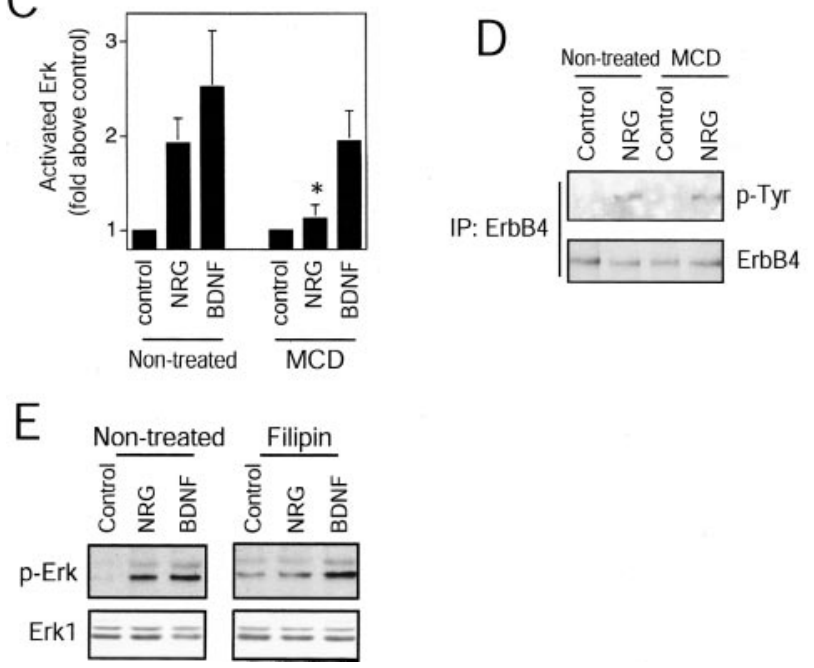

Figure 7. Specific inhibition of NRG-induced Erk activation by lipid raft disruption. A, Disruption of lipid rafts by MCD. Cortical neurons were pretreated without or with $10 \mathrm{~mm} \mathrm{MCD} \mathrm{for} 15$ min and stimulated without or with $10 \mathrm{~nm} \mathrm{NRG} \mathrm{for} 15 \mathrm{~min}$. Control and treated neurons were lysed. Lysates were subjected to OptiPrep gradient centrifugation after incubation with Triton $X$-100. Raft (top) and soluble (bottom) fractions were analyzed by SDS-PAGE and immunoblotting. $B$, Inhibition of NRG-induced Erk activation in MCD-treated neurons. Neurons were pretreated without (left) or with (right) $10 \mathrm{~mm} \mathrm{MCD} \mathrm{for} 15$ min and stimulated with $10 \mathrm{~nm}$ NRG for $15 \mathrm{~min}$. Lysates were resolved on SDS-PAGE and probed with anti-phospho-Erk (p-Erk). C, Quantitative analysis of data in $B$ (mean $\pm \mathrm{SEM} ; n=4$ independent experiments). The image was analyzed as described in Materials and Methods. The density of $p$-Erk was normalized to total Erk1. Comparing NRG in groups in "Non-treated" and "MCD" conditions, ${ }^{*} p<0.05$; unpaired $t$ test. $D$, Effect of MCD on phosphotyrosine level of ErbB4. Neurons were pretreated with $10 \mathrm{~mm}$ MCD for $15 \mathrm{~min}$ and stimulated with or without $10 \mathrm{~nm}$ NRG for 15 min. Lysates were immunoprecipitated with anti-ErbB4 antibody. The immunoprecipitates were resolved on SDSPAGE and probed with anti-phosphotyrosine antibody ( $p$-Tyr). E, Inhibition of NRG-induced Erk activation in filipin-treated neurons. Neurons were pretreated without (left) or with (right) 0.1 $\mu \mathrm{g} / \mathrm{ml}$ filipin for $30 \mathrm{~min}$ and stimulated with $10 \mathrm{~nm} \mathrm{NRG} \mathrm{for} 15 \mathrm{~min}$. Western blot was done as in $B . A, B, D$, and $E$ show representative blots from three independent experiments with similar results.

SPs, evoked by stimulating Schaffer collateral input, from the CA1 stratum radiatum. The hippocampal slices were superfused in ACSF with a final concentration of $0.1 \mathrm{~mm} \mathrm{MCD}$, a concentration at which we established that MCD had no effect on basal fEPSP slope (98 $\pm 1.4 \%$, mean \pm SEM, of baseline level after 20 min of MCD; $n=7$ slices) or on post-tetanic potentiation (data not shown). LTP was induced by tetanic stimulation (two 500 msec, $100 \mathrm{~Hz}$ trains) delivered to the Schaffer collateral input. This stimulation produced LTP in slices treated with MCD (0.1 $\mathrm{mM}$ ): fEPSP slope was $128 \pm 4.6 \%$ (mean \pm SEM; $n=12$ slices) of the baseline level 55 min after tetanus (Fig. $8 A, B$ ). Although the level of potentiation in slices treated with $\mathrm{MCD}(0.1 \mathrm{~mm})$ was less than that in slices without MCD (fEPSP slope $147 \pm 4.4 \%$; $n=10$ slices), this concentration of MCD permitted reliable LTP without affecting basal synaptic transmission or short-term plasticity and was sufficient to deplete ErbB4 from the lipid raft fractions in cultured cortical neurons (Fig. 8D).

After we had established these experimental conditions, we bath-applied NRG ( $2 \mathrm{nM}$, starting 20 min before tetanus) without or with treatment with MCD. Without MCD, during NRG application fEPSP slope was $108 \pm 3.6 \%$ of the baseline level $55 \mathrm{~min}$ after tetanus ( $n=9$ slices), indicating that NRG suppressed LTP to $18 \pm 7.2 \%$ of the control level (Fig. $8 \mathrm{C}$ ), consistent with the reported inhibitory effect of NRG on LTP induction (Huang et al., 2000). In contrast, in slices treated with MCD, NRG application did not affect induction of LTP. During NRG with MCD, the fEPSP slope $55 \mathrm{~min}$ after tetanus was $123 \pm 5.0 \%$ of the baseline level, which was not different from that in slices with MCD alone (Fig. $8 A-C$ ). Thus, we concluded that MCD prevented NRGinduced suppression of the induction of LTP.

\section{Discussion}

In this study we show that ErbB4 is localized at the anatomically defined PSD in the brain and present in lipid rafts within neuronal plasma membranes. Importantly, NRG induces translocation of ErbB4 and adaptor signaling molecules into lipid rafts in cultured neurons. Disruption of lipid rafts inhibits NRG-induced activation of Erk and prevents NRG-induced suppression of LTP. These results suggest that the ligand-induced translocation of ErbB4 and associated signaling molecules into lipid rafts is critical in NRG signaling.

The plasma membrane is a fluid bilayer of phospholipids within which integral membrane proteins diffuse. Scattered within the disordered fluid phase of the lipid bilayer are small highly ordered lipid rafts (Simons and Ikonen, 1997; Brown and London, 1998). Proteins that concentrate in lipid rafts include glycosylphosphatidylinositol (GPI)-linked proteins (Hooper, 1999; Tansey et al., 2000; Paratcha et al., 2001), doubly acylated proteins such as $\alpha$ subunits of heterotrimeric G-proteins and Src-family kinases (Resh, 1999), and cholesterol-linked and palmitoylated proteins such as Hedgehog (Brown and London, 1998). Concentrating molecules in lipid rafts allows them to interact to coordinate signal transduction, thus compartmentalizing signaling and membrane trafficking (Simons and Toomre, 2001). Lipid rafts are involved in signaling processes initiated by IgE during the allergic immune response (Baird et al., 1999), T-cell antigen receptor activation (Janes et al., 2001; Langlet et al., 2001), and GDNF receptor activation (Tansey et al., 2000; Paratcha et al., 2001). Lipid rafts in epithelial cells may bring GPI-anchored and transmembrane proteins to the apical membrane (Lisanti et al., 1990; Kundu et al., 1996; Scheiffele et al., 1997). Recently, NRG was identified as a lipid raft-associated protein in rat brain and transfected cells (Frenzel and Falls, 2001), and ErbB4 is localized in caveolin-associated microdomain in cardiac myocytes (Zhao et al., 1999). ErbB2 and ErbB4 become associated with the Triton-insoluble fraction after ligand stimulation in T47D cells (Zhou and Carpenter, 2000, 2001). These findings together with results presented in this paper suggest that lipid rafts play an important role in NRG signaling. This notion is supported by several lines of evidence. First, in comparison with non-raft membranes, ErbB4 is tyrosine phosphorylated at a higher level in lipid rafts (Fig. $4 E$ ) or in detergent-insoluble membrane fractions (Zhou and Carpenter, 2000), suggesting that ErbB4 remains activated in lipid rafts. Second, in addition to ErbB4, NRG stimulation recruits the adaptor proteins Shc and 

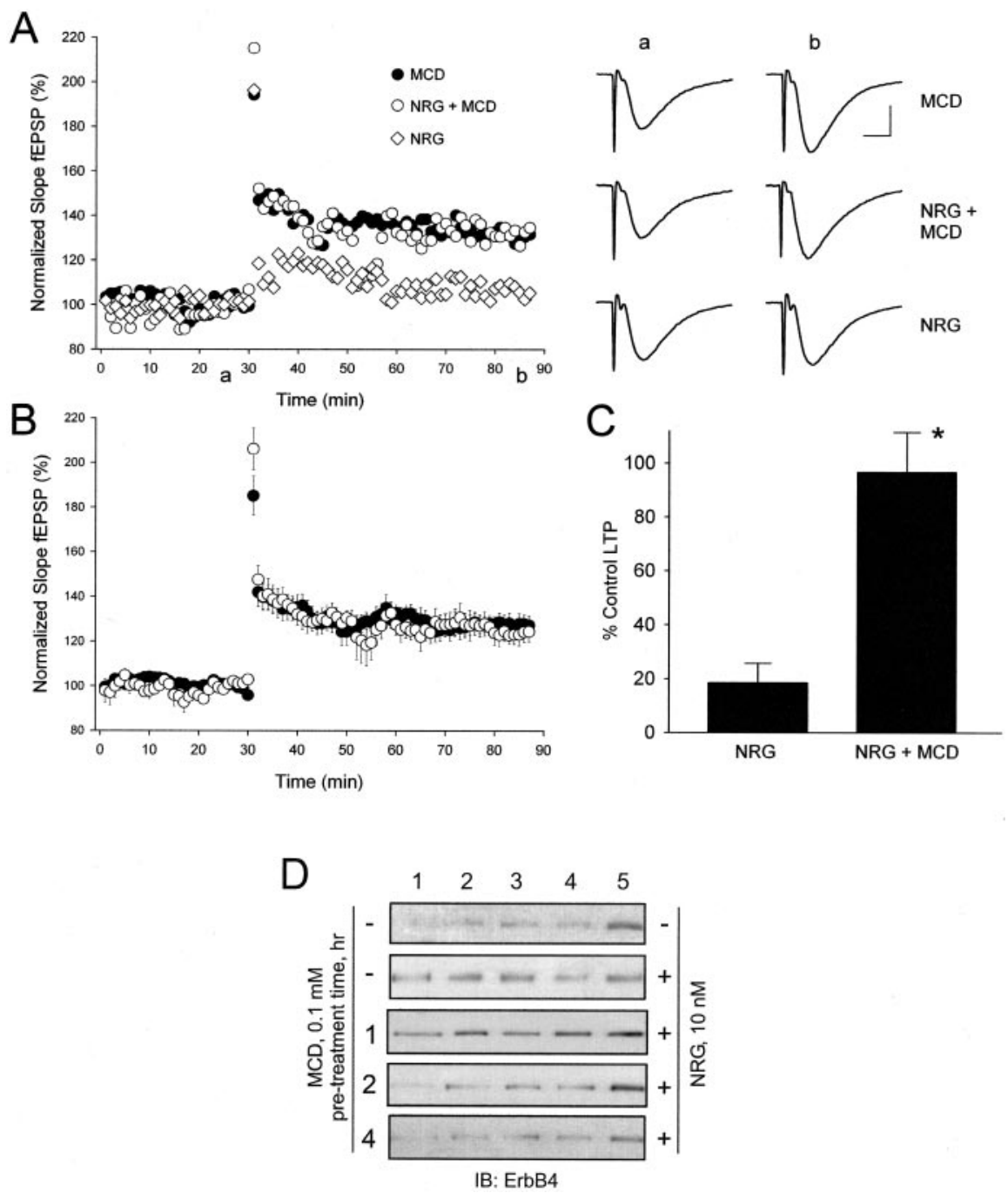

Figure 8. MCD prevents NRG-mediated suppression of tetanus-induced LTP in CA1 hippocampus. A, Normalized fEPSP slope is plotted every 1 min for slices treated with NRG with or without MCD, or with MCD alone. When present, $M C D(0.1 \mathrm{~mm})$ was in ACSF during the entire experiment (beginning 30 min before tetanus), whereas NRG ( $2 \mathrm{nM}$ ) was applied starting 20 min before tetanus. Tetanic stimulation was delivered to Schafer collateral-CA1 synapses at the 30 min time point. fEPSP slope was normalized with respect to the mean slope of fEPSPs recorded during the 10 min period immediately before tetanus. On the right, averaged fEPSP traces recorded before $(a)$ or after $(b)$ tetanus are shown. Calibration: $5 \mathrm{msec}, 0.5 \mathrm{mV}$. B, Normalized fEPSP slope (mean \pm SEM) plotted every 1 min from slices treated with NRG and $\operatorname{MCD}(n=6 ; \bigcirc)$ or MCD alone $(n=12 ; 0)$. The concentration and time of administration of NRG and MCD are the same as in A. C, Histogram shows effect of NRG on mean increase in fEPSP slope in slices without versus with $M C D\left({ }^{*} p<0.001\right.$; unpaired $t$ test). Results for NRG are expressed as a percentage of the tetanus-induced increase in fEPSP slope (mean \pm SEM) in slices in the respective control group in which NRG was not applied, without or with MCD. Data are taken 55 min after tetanus. D, Western blotting analyses of MCD-pretreated neuronal fractions. To determine whether 0.1 $\mathrm{mm}$ MCD was able to disrupt lipid rafts, cultured cortical neurons were pretreated with MCD for the indicated times and stimulated with $10 \mathrm{~nm} \mathrm{NRG} \mathrm{for} 15 \mathrm{~min}$. Control and treated neurons were lysed. Lysates were subjected to OptiPrep gradient centrifugation after incubation with Triton X-100 and analyzed by SDS-PAGE and immunoblotting.

Grb2 into lipid rafts, presumably via binding to tyrosinephosphorylated ErbB4 (Fig. $4 F$ ). These adaptor proteins are important for NRG bioactivity (Si et al., 1996; Tansey et al., 1996; Altiok et al., 1997; Si and Mei, 1999). Third, NRG-induced Erk activation is attenuated in cultured neurons when lipid rafts are disrupted by MCD or filipin (Fig. 7). Because MCD had no effect on tyrosine phosphorylation of ErbB4, lipid rafts may not be crucial for activation of the kinase but are important for downstream signaling. Last, disruption of lipid rafts prevents NRGstimulated suppression of LTP induction at Schaffer collateralCA1 synapses (Fig. 8).

Electron microscopic results in this study demonstrate that
ErbB4 is localized in the anatomically defined PSD, consistent with previous results that ErbB4 is a component of the biochemical PSD (Garcia et al., 2000; Huang et al., 2000). Interestingly, although the PSD can be further fractioned into lipid raft and non-raft fractions, ErbB4 and its interacting protein PSD-95 are present in the lipid raft fraction in the PSD (Fig. 5), in contrast to their distribution in both raft and non-raft fractions in brain membranes (Fig. 3). These results suggest that lipid rafts are an important structural component of the PSD. Although ErbB4 is enriched in lipid rafts in the brain, it is mainly distributed in nonraft components in naive neurons in culture (Fig. 4). On stimulation with NRG, ErbB4 translocates into the lipid raft fraction, which suggests that the recruitment of ErbB4 into lipid raft microdomains of the plasma membrane is regulated by the ligand NRG. In the brain, ErbB4 is enriched in lipid rafts, which may be caused by a basal level of NRG stimulation in vivo or interaction with PSD-95. Thus, we suggest that ErbB4 receptors are distributed in non-raft domains in the absence of NRG and become partitioned in lipid rafts in response to NRG stimulation. Lipid rafts may be vehicles for ErbB4 translocation into the PSD. Once recruited, ErbB4 is anchored in the PSD via the interaction with PSD-95. We speculate that lipid rafts may be critical for sorting ErbB4 into the PSD and for retention of and signaling by ErbB4 at excitatory synapses.

The present electron microscopic studies demonstrate that ErbB4 in adult brain is localized in PSDs of dendritic spines as well as at shaft synapses. Because dendritic spines are found virtually exclusively on excitatory neurons (Zhang and Benson, 2000; Nimchinsky et al., 2002), these results demonstrate that ErbB4 is present postsynaptically at glutamatergic synapses onto excitatory neurons.

Our study provides evidence about the mechanisms by which NRG inhibits induction of LTP at Schaffer collateral-CA1 synapses (Huang et al., 2000). Because NRG has no effect on basal synaptic transmission through AMPA or NMDA receptors, paired-pulse facilitation, or post-tetanic potentiation at these synapses (Huang et al., 2000), our working model is that NRG activation of ErbB4 receptors interrupts the signaling cascade that induces LTP. We find that lipid rafts are required for the ErbB4 signaling in PSDs that is linked to interrupting the induction of LTP. Because NRG induces ErbB4 and associated signaling molecules to translocate into the lipid rafts, NRG may inhibit LTP induction via signaling pathways in the raft subcompartment of the PSD. At Schaffer collateral-CA1 synapses, induction of LTP is dependent on activation of NMDA receptors and requires many additional signaling proteins local- 
ized in the PSD (Malenka and Nicoll, 1999; Scannevin and Huganir, 2000; Soderling and Derkach, 2000; Ali and Salter, 2001). We suggest that ErbB4 signaling machinery can be brought to interact with and inhibit the function of signaling proteins implicated in LTP induction and concentrated in lipid rafts (Resh, 1999), including Src, Fyn, and Erk. Activity-dependent persistent enhancement of glutamatergic synaptic transmission, of which LTP is a dominant model, is pervasive in the nervous system; thus, our present findings may apply to the regulation of excitatory synaptic transmission throughout the CNS.

\section{References}

Adlkofer K, Lai C (2000) Role of neuregulins in glial cell development. Glia 29:104-111.

Ali DW, Salter MW (2001) NMDA receptor regulation by Src kinase signaling in excitatory synaptic transmission and plasticity. Curr Opin Neurobiol 11:336-342.

Altiok N, Bessereau JL, Changeux JP (1995) ErbB3 and ErbB2/neu mediate the effect of heregulin on acetylcholine receptor gene expression in muscle: differential expression at the endplate. EMBO J 14:4258-4266.

Altiok N, Altiok S, Changeux JP (1997) Heregulin-stimulated acetylcholine receptor gene expression in muscle: requirement for MAP kinase and evidence for a parallel inhibitory pathway independent of electrical activity. EMBO J 6:717-725.

Baird B, Sheets ED, Holowka D (1999) How does the plasma membrane participate in cellular signaling by receptors for immunoglobulin E. Biophys Chem 82:109-119.

Banker GA, Cowan WM (1977) Rat hippocampal neurons in dispersed cell culture. Brain Res 126:397-425.

Blackstone CD, Moss SJ, Martin LJ, Levey AI, Price DL, Huganir RL (1992) Biochemical characterization and localization of a non- $\mathrm{N}$-methyl-Daspartate glutamate receptor in rat brain. J Neurochem 58:1118-1126.

Boutros M, Mlodzik M (1999) Dishevelled: at the crossroads of divergent intracellular signaling pathways. Mech Dev 83:27-37.

Brown DA, London E (1998) Functions of lipid rafts in biological membranes. Ann Rev Cell Dev Biol 14:111-136.

Bruckner K, Pablo Labrador J, Scheiffele P, Herb A, Seeburg PH, Klein R (1999) EphrinB ligands recruit GRIP family PDZ adaptor proteins into raft membrane microdomains. Neuron 22:511-524.

Buonanno A, Fischbach GD (2001) Neuregulin and ErbB receptor signaling pathways in the nervous system. Curr Opin Neurobiol 11:287-296.

Cohen BD, Green JM, Foy L, Fell HP (1996) HER4-mediated biological and biochemical properties in NIH 3T3 cells. Evidence for HER1-HER4 heterodimers. J Biol Chem 271:4813-4818.

Craven SE, Bredt DS (1998) PDZ proteins organize synaptic signaling pathways. Cell 93:495-498.

Fischbach GD, Rosen KM (1997) ARIA: a neuromuscular junction neuregulin. Annu Rev Neurosci 20:429-458.

Frenzel KE, Falls DL (2001) Neuregulin-1 proteins in rat brain and transfected cells are localized to lipid rafts. J Neurochem 77:1-12.

Garcia RAG, Vasudevan K, Buonanno A (2000) The neuregulin receptor ErbB4 interacts with PDZ-containing proteins at neuronal synapses. Proc Natl Acad Sci USA 97:3596-3601.

Garner CC, Nash J, Huganir RL (2000) PDZ domains in synapse assembly and signaling. Trends Cell Biol 10:274-280.

Garratt AN, Britsch S, Birchmeier C (2000) Neuregulin, a factor with many functions in the life of a Schwann cell. BioEssays 22:987-996.

Gassmann M, Casagranda F, Orioli D, Simon H, Lai C, Klein R, Lemke G (1995) Aberrant neural and cardiac development in mice lacking the ErbB4 neuregulin receptor. Nature 378:390-394.

Gerecke KM, Wyss JM, Karavanova I, Buonanno A, Carroll SL (2001) ErbB transmembrane tyrosine kinase receptors are differentially expressed throughout the adult rat central nervous system. J Comp Neurol 433:86-100.

Holmes WE, Slikowski MX, Akita RW, Kenzel WJ, Lee J, Park JW, Yansura D, Abadi N, Raab H, Lewis GD, Shepard HM, Huang WJ, Wood WJ, Goeddel DV, Vandlen RL (1992) Identification of heregulin, a specific activator of p185erbB2. Science 256:1205-1210.

Hooper NM (1999) Detergent-insoluble glycosphingolipid/cholesterolrich membrane domains, lipid rafts and caveolae. Mol Membr Biol $16: 145-156$.
Huang Y, Wang Q, Won S, Luo Z, Xiong W, Mei L (2002) Compartmentalized NRG signaling and PDZ domain-containing proteins in synapse structure and function. Int J Dev Neurosci 20:173-185.

Huang YZ, Won S, Ali DW, Wang Q, Tanowitz M, Du QS, Pelkey KA, Yang DJ, Xiong WC, Salter MW, Mei L (2000) Regulation of neuregulin signaling by PSD-95 interacting with ErbB4 at CNS synapses. Neuron 26:443-455.

Huang YZ, Wang Q, Xiong WC, Mei L (2001) Erbin is a protein concentrated at postsynaptic membranes that regulates surface expression of ErbB2. J Biol Chem 276:19318-19326.

Janes PW, Ley SC, Magee AI, Kabouridis PS (2001) The role of lipid rafts in $\mathrm{T}$ cell antigen receptor (TCR) signaling. Semin Immunol 12:23-34.

Jones JT, Ballinger MD, Pisacane PI, Lofgren JA, Fitzpatrick VD, Fairbrother WJ, Wells JA, Sliwkowski MX (1998) Binding interaction of the heregulin beta egf domain with ErbB3 and ErbB4 receptors assessed by alanine scanning mutagenesis. J Biol Chem 273:11667-11674.

Kellenberger E (1991) The potential of cryofixation and freeze substitution: observations and theoretical considerations. J Microsc 161:183-203.

Kennedy MB (1997) The postsynaptic density at glutamatergic synapses. Trends Neurosci 20:264-268.

Kharazia VN, Weinberg RJ (1999) Immunogold localization of AMPA and NMDA receptors in somatic sensory cortex of albino rat. J Comp Neurol 412:292-302.

Kramer R, Bucay N, Kane DJ, Martin LE, Tarpley JE, Theil LE (1996) Neuregulins with an Ig-like domain are essential for mouse myocardial and neuronal development. Proc Natl Acad Sci USA 93:4833-4838.

Kundu A, Avalos RT, Sanderson CM, Nayak DP (1996) Transmembrane domain of influenza virus neuraminidase, a type II protein, possesses an apical sorting signal in polarized MDCK cells. J Virol 70:6508-6515.

Langlet C, Bernard AM, Drevot P, He HT (2001) Membrane rafts and signaling by the multichain immune recognition receptors. Curr Opin Immunol 12:250-255.

Lee HJ, Jung KM, Huang YZ, Bennett LB, Lee JS, Mei L, Kim TW (2002) Presenilin-dependent gamma-secretase-like intramembrane cleavage of ErbB4. J Biol Chem 277:6318-6323.

Lee KF, Simon H, Chen H, Bates B, Hung MC, Hauser C (1995) Requirement for neuregulin receptor erbB2 in neural and cardiac development. Nature 378:394-398.

Lemke G (2001) Glial control of neuronal development. Annu Rev Neurosci 24:87-105.

Lisanti MP, Caras IW, Gilbert T, Hanzel D, Rodriguez-Boulan E (1990) Vectorial apical delivery and slow endocytosis of a glycolipid-anchored fusion protein in transfected MDCK cells. Proc Natl Acad Sci USA 87:7419-7423.

Lu YM, Roder JC, Davidow J, Salter MW (1998) Src activation in the induction of long-term potentiation in CA1 hippocampal neurons. Science 279:1363-1368.

Malenka RC, Nicoll RA (1999) Long-term potentiation-a decade of progress? Science 285:1870-1874.

Meyer D, Birchmeier C (1995) Multiple essential functions of neuregulin in development. Nature 378:386-390.

Morris JK, Lin W, Hauser C, Marchuk Y, Getman D, Lee KF (1999) Rescue of the cardiac defect in ErbB2 mutant mice reveals essential roles of ErbB2 in peripheral nervous system development. Neuron 23:273-283.

Moscoso LM, Chu GC, Gautam M, Noakes PG, Merlie JP, Sanes JR (1995) Synapse-associated expression of an acetylcholine receptor-inducing protein, ARIA/heregulin, and its putative receptors, ErbB2 and ErbB3, in developing mammalian muscle. Dev Biol 172:158-169.

Naisbitt S, Valtschanoff J, Allison DW, Sala C, Kim E, Craig AM, Weinberg RJ, Sheng M (2000) Interaction of the postsynaptic density-95/guanylate kinase domain-associated protein complex with a light chain of myosin- $\mathrm{V}$ and dynein. J Neurosci 20:4524-4534.

Ni CY, Murphy MP, Golde TE, Carpenter G (2001) gamma-Secretase cleavage and nuclear localization of ErbB-4 receptor tyrosine kinase. Science 294:2179-2181.

Nimchinsky EA, Sabatini BL, Svoboda K (2002) Structure and function of dendritic spines. Annu Rev Physiol 64:313-353.

Paratcha G, Ledda F, Baars L, Coulpier M, Besset V, Anders J, Scott R, Ibanez CF (2001) Released GFRalphal potentiates downstream signaling, neuronal survival, and differentiation via a novel mechanism of recruitment of c-Ret to lipid rafts. Neuron 29:171-184.

Park H, Go YM, St John PL, Maland MC, Lisanti MP, Abrahamson DR, Jo H 
(1998) Plasma membrane cholesterol is a key molecule in shear stressdependent activation of extracellular signal-regulated kinase. J Biol Chem 273:32304-32311.

Perez AS, Bredt DS (1998) The N-terminal PDZ-containing region of postsynaptic density-95 mediates association with caveolar-like lipid domains. Neurosci Lett 258:121-123.

Phend KD, Weinberg RJ, Rustioni A (1992) Techniques to optimize postembedding single and double staining for amino acid neurotransmitters. J Histochem Cytochem 40:1011-1020.

Phend KD, Rustioni A, Weinberg RJ (1995) An osmium-free method of Epon embedment that preserves both ultrastructure and antigenicity for postembedding immunocytochemistry. J Histochem Cytochem 43:283-292.

Resh MD (1999) Fatty acylation of proteins: new insights into membrane targeting of myristoylated and palmitoylated proteins. Biochim Biophys Acta 1451:1-16.

Sambrook J, Fritsch EF, Maniatis T (1989) Molecular cloning: a laboratory manual. Cold Spring Harbor, NY: Cold Spring Harbor Laboratory.

Scannevin RH, Huganir RL (2000) Postsynaptic organization and regulation of excitatory synapses. Nat Rev Neurosci 1:133-141.

Scheiffele P, Roth MG, Simons K (1997) Interaction of influenza virus hemagglutinin with sphingolipid-cholesterol membrane domains via its transmembrane domain. EMBO J 16:5501-5508.

Sheng M, Sala C (2001) PDZ domains and the organization of supramolecular complexes. Annu Rev Neurosci 24:1-29.

Si J, Mei L (1999) ERK MAP kinase activation is required for ARIA-induced increase in all five AChR subunit mRNAs as well as synapse-specific expression of the AChR e-transgene. Mol Brain Res 67:18-27.

Si J, Luo Z, Mei L (1996) Induction of acetylcholine receptor gene expression by ARIA requires activation of mitogen-activated protein kinase. J Biol Chem 271:19752-19759.

Simons K, Ikonen E (1997) Functional rafts in cell membranes. Nature 387:569-572.

Simons K, Toomre D (2001) Lipid rafts and signal transduction. Nat Rev Mol Cell Biol 1:31-39.

Soderling TR, Derkach VA (2000) Postsynaptic protein phosphorylation and LTP. Trends Neurosci 23:75-80.

Stefansson H, Sigurdsson E, Steinthorsdottir V, Bjornsdottir S, Sigmundsson T, Ghosh S, Brynjolfsson J, Gunnarsdottir S, Ivarsson O, Chou TT, Hjaltason $\mathrm{O}$, Birgisdottir B, Jonsson H, Gudnadottir VG, Gudmundsdottir E, Bjornsson A, Ingvarsson B, Ingason A, Sigfusson S, Hardardottir H, et al. (2002) Neuregulin 1 and susceptibility to schizophrenia. Am J Hum Genet 71:877-892.
Suzuki T (2002) Lipid rafts at postsynaptic sites: distribution, function and linkage to postsynaptic density. Neurosci Res 44:1-9.

Sweeney C, Lai C, Riese II DJ, Diamonti AJ, Cantley LC, Carraway III KL (2000) Ligand discrimination in signaling through an ErbB4 receptor homodimer. J Biol Chem 275:19803-19807.

Tanowitz M, Si J, Yu D-H, Feng G-S, Mei L (1999) Regulation of neuregulin-mediated AChR synthesis by protein tyrosine phosphatase SHP2. J Neurosci 19:9426-9435.

Tansey MG, Chu GC, Merlie JP (1996) ARIA/HRG regulates AChR epsilon subunit gene expression at the neuromuscular synapse via activation of phosphatidylinositol 3-kinase and Ras/MAPK pathway. J Cell Biol 134:465-476.

Tansey MG, Baloh RH, Milbrandt J, Johnson Jr EM (2000) GFRalphamediated localization of RET to lipid rafts is required for effective downstream signaling, differentiation, and neuronal survival. Neuron 25:611-623.

Trinidad JC, Fischbach GD, Cohen JB (2000) The agrin/MuSK signaling pathway is spatially segregated from the neuregulin/ErbB receptor signaling pathway at the neuromuscular junction. J Neurosci 20:8762-8770.

ValtschanoffJG, Burette A, Wenthold RJ, Weinberg RJ (1999) Expression of NR2 receptor subunit in rat somatic sensory cortex: synaptic distribution and colocalization with NR1 and PSD-95. J Comp Neurol 410:599-611.

Woldeyesus MT, Britsch S, Riethmacher D, Xu L, Sonnenberg-Riethmacher E, Abou-Rebyeh F, Harvey R, Caroni P, Birchmeier C (1999) Peripheral nervous system defects in erbB2 mutants following genetic rescue of heart development. Genes Dev 13:2538-2548.

Wolpowitz D, Mason TB, Dietrich P, Mendelsohn M, Talmage DA, Role LW (2000) Cysteine-rich domain isoforms of the neuregulin-1 gene are required for maintenance of peripheral synapses. Neuron 25:79-91.

Zhang W, Benson DL (2000) Development and molecular organization of dendritic spines and their synapses. Hippocampus 10:512-526.

Zhao YY, Feron O, Dessy C, Han X, Marchionni MA, Kelly RA (1999) Neuregulin signaling in the heart. Dynamic targeting of erbB4 to caveolar microdomains in cardiac myocytes. Circ Res 84:1380-1387.

Zhou W, Carpenter G (2000) Heregulin-dependent trafficking and cleavage of ErbB-4. J Biol Chem 275:34737-34743.

Zhou W, Carpenter G (2001) Heregulin-dependent translocation and hyperphosphorylation of ErbB-2. Oncogene 20:3918-3920.

Zhu X, Lai C, Thomas S, Burden SJ (1995) Neuregulin receptors, erbB3 and erbB4, are localized at neuromuscular synapses. EMBO J 14:5842-5848. Ziff EB (1997) Enlightening the postsynaptic density. Neuron 19:1163-1174. 